\title{
Climate Strategy - Between Ambition and Realism
}


Climate Strategy - Between Ambition and Realism 
The Webpublications series comprises studies carried out as part of the activities of the WRR.

Responsibility for the content and the views expressed rests with the authors. A list of all Webpublications can be found on the WRR website (www.wrr.nl).

Scientific Council for Government Policy (WRR)

Lange Vijverberg 4-5

PO Box 20004

2500 EA The Hague

Telephone 070-356 4600

Fox 070-356 4685

E-mail info@wrr.nl

Website http://www.wrr.nl 


\section{WRR}

SCIENTIFIC COUNCIL FOR GOVERNMENT POLICY

\section{Climate Strategy - Between Ambition and Realism}


Cover design / Lay-out: Studio Daniëls, The Hague

ISBN 9789053561683

NUR 741

(C) WRR/ AUP, The Hague/ Amsterdam 2007

All rights reserved. Without limiting the rights under copyright reserved above, no part of this book may be reproduced, stored in or introduced into a retrieval system, or transmitted, in any form or by any means (electronic, mechanical, photocopying, recording or otherwise) without the written permission of both the copyright owner and the author of the book. 


\section{PREFACE}

This booklet provides the reader with an extensive summary of the Dutch report on climate strategy, published in June 2006, by the Netherlands Scientific Council for Government Policy (known as the WRR in Dutch). The WRR is an advisory body, which regularly publishes reports. The council seeks to propose a critical, futureoriented re-appraisal of the assumptions that guide current policy strategies of the Dutch government.

The report on climate strategy was prepared by an internal working group at the WRR. The members of the working group were Prof. J.L.M. Pelkmans (Council member), P.A. van Driel, Dr. R.M.A. J answeijer and Dr. D. Scheele (staff officers). In addition, W.C. Kersten and Prof. Dr. P. Winsemius were members of the project group in the initial phase of the project, while Messrs O. Klinkenberg and C. Veld contributed to the project as work in placement trainees.

External experts were consulted on a number of specific issues in the preperation stage. The working group would like to thank the following individuals for sharing their knowledge and expertise: Prof.J.C.J.M. van den Bergh (VU), M. Berk (MNP), H.C.Y.M. Bersee (VROM), Dr. E. Boeker (WBS), I. Breuers (NWO), J. Brinkhoff (EZ), Dr. W. ten Brinke (RIZA), Dr. J.J.C. Bruggink (ECN), Dr. J. Dronkers (RIKZ), Prof. T. van der Hagen (RID), B. Hanssen (AER), Prof. E.C. van Ierland (WUR), J.M. Pinkse (UVA), Prof. R. Rabbing (WUR), L.G. van Schaik (CEPS), Dr. S. Slingerland (CE), J . van der Sommen (NWP), Dr. R. Steur (EZ), J. Veraart (WUR), prof. J.M. Verschuren, A.M. Versteegh (NRG), L. Voogt (RIKZ), M.F.M. van Wortel (V\&W) and R. Ybema $(\mathrm{ECN})$.

Although the working group made grateful use of the knowledge of these experts, this report falls under the responsibility of the Council.

The WRR is very grateful to Julian Ross, who helped with the editorial and translation work needed to create the right context fot htis English language compilation.

Prof. Wim B.H.J. van de Donk

Chairman WRR 



\section{CONTENTS}

$\begin{array}{ll}\text { Preface } & 5\end{array}$

$\begin{array}{lr}\text { Summary } & 9\end{array}$

$1 \quad$ Introduction $\quad 15$

$\begin{array}{lll}1.1 & \text { The climate problem } & 15\end{array}$

$\begin{array}{lll}1.2 & \text { Climate policy } & 15\end{array}$

$\begin{array}{lll}1.3 & \text { Questions addressed in the report }\end{array}$

$\begin{array}{lll}1.4 & \text { Structure of the report } & 18\end{array}$

$2 \quad$ Problem definition and policy 19

$\begin{array}{lll}2.1 & \text { Knowledge about the climate } & 19\end{array}$

$\begin{array}{lll}2.2 & \text { Difficult choices } & 20\end{array}$

2.2.1 Problems in deciding between adaptation and emission reduction 20

2.2.2 The precautionary principle as an answer to uncertainty 22

$\begin{array}{lll}2.2 .3 & \text { Ethical considerations } & 22\end{array}$

2.2.4 The political decision-making process 24

$\begin{array}{lll}2.3 & \text { Policy progress to date } & 25\end{array}$

2.3.1 The position of the EU 25

$\begin{array}{lll}2.3 .2 & \text { Dutch policy } & 27\end{array}$

$3 \quad$ adapting to a changing climate 29

$\begin{array}{lll}3.1 & \text { Introduction } & 29\end{array}$

$\begin{array}{lll}3.2 & \text { The policy agenda for adaptation } & 29\end{array}$

$\begin{array}{lll}3.3 & \text { Water as a physical planning problem } & 36\end{array}$

$\begin{array}{lll}\text { 3.3.1 Standards for water management } & 36\end{array}$

$\begin{array}{lll}3.4 & \text { Water as an administrative problem } & 40\end{array}$

$\begin{array}{ll}3.4 .1 & \text { Legal instruments }\end{array}$

$\begin{array}{lll}3.4 .2 & \text { Public support } & 41\end{array}$

3.4.3 Administrative coordination at international level 42

4 Emission reduction as a technical strategic issue 45

4.1 Introduction 45

4.2 The emission reduction challenge for fossil $\mathrm{co}_{2} \quad 46$

4.2.1 The period up to 2030-2050 is crucial for the $2{ }^{\circ} \mathrm{C}$ target 46

4.2.2 The gulf compared with 'business as usual' 46 
$\begin{array}{lll}4.3 & \text { Route 1: greater energy efficiency } & 47\end{array}$

4.4 Route 2: altering the global energy mix 48

4.4.1 Key conditions: coal, electricity, developing countries 48

$\begin{array}{ll}\text { 4.4.2 Results via the energy mix } & 51\end{array}$

4.4.3 Separating emission reduction and energy transition 53

4.5 Route 3: deforestation, afforestation and land-based carbon storage $\quad 54$

4.6 Route 4: reducing emissions of oggs: the example of methane 55

$4.7 \quad$ Emission reduction strategy up to $2050 \quad 56$

$5 \quad$ International coordination of climate policy 59

5.1 Introduction $\quad 59$

5.2 A closer look at the global coordination problem 59

5.2.1 Definition and characterisation of coordination $\quad 59$

$\begin{array}{lll}5.2 .1 \quad \text { Complicating factors } & 61\end{array}$

$\begin{array}{ll}\text { 5.2.2 Conditions for effective coordination } & 61\end{array}$

$\begin{array}{lll}5.3 & \text { The principal players: interests and policy } & 62\end{array}$

5.3.1 Diversity in the energy structure of the Big Eight 62

5.3.2 The position of the United States 66

$\begin{array}{lll}\text { 5.3.3 The position of China } & 67\end{array}$

5.3.4 The position of the European Union 68

$\begin{array}{lll}\text { 5.3.5 The positions compared } & 69\end{array}$

$\begin{array}{lll}5.4 & \text { Institutions and strategic options for global climate policy } & 70\end{array}$

$\begin{array}{lll}\text { 5.4.1 Montreal versus Kyoto } & 70\end{array}$

$\begin{array}{lll}\text { 5.4.2 Building on the UNFCCC } & 71\end{array}$

$\begin{array}{lll}\text { 5.4.3 Multicoloured flexibility } & 74\end{array}$

$\begin{array}{lll}\text { 5.4.4 Institutionalisation of global coordination } & 77\end{array}$

$\begin{array}{lll}\text { 5.4.5 Coalition formation and leadership } & 77\end{array}$

$6 \quad$ A Dutch and European climate strategy 79

$\begin{array}{lll}6.1 & \text { Climate strategy requires ambition and realism } & 79\end{array}$

$\begin{array}{lll}6.2 & \text { High priority for adaptation } & 81\end{array}$

6.3 Emission reduction: routes and timeframes 83

$\begin{array}{lll}6.4 & \text { The efficacy of global coordination } & 87\end{array}$

6.5 How a small country can be great 92

$\begin{array}{lr}\text { Bibliography } & 93\end{array}$ 


\section{SUM M ARY}

There are strong indications that the climate is changing, partly under the influence of human activity. A substantial reduction in emissions of greenhouse gases is required in order to slow down the rate of climate change sufficiently. However, while the total global volume of $\mathrm{CO}_{2}$ emissions needs to fall sharply, they are expected to increase steeply as a result of rising prosperity and population growth. There are considerable uncertainties and all manner of complicating factors which make it difficult to formulate an effective climate strategy. The magnitude of the climate effects (and sometimes the direction in which they operate) is difficult to predict. There are large gaps in our knowledge about the climate system, partly due to the extreme slowness of that system. This raises the danger of setting in motion irreversible changes. The problem of policy formulation is also exacerbated by the global setting in which it has to be achieved. Different countries have widely diverging interests and consistently place the emphasis on economic growth, leading to an increase rather than a decrease in greenhouse gas emissions. Moreover, international coordination of emission reduction efforts is problematic, which could well lead to in adequate policy. These uncertainties and complicating factors could en gender high costs. Given these uncertainties, climate policy ought to strive not only for optimisation, but also robustness. A robust strategy is aimed at effectiveness in a wide variety of potential scenarios.

\section{Difficult judgments}

There are wide differences in the way individual countries view the climate issue. The global divergence in perceptions, interests and preferences can make it difficult to formulate an effective climate strategy. The effectiveness of that strategy depends on the goals that countries pursue, and reaching agreement on them (in the sense of hard commitment) will not be easy. Differences in perceptions and preferences can lead to unbridgeable differences in the degree of willingness to bear the costs. One of the problems when deciding on the cost distribution is that both the costs of adaptation and of reducing the rate of climate change are unclear. Moreover, policymakers have to weigh those costs against completely different objectives which also require government intervention (economic growth, education, health care, infrastructure, pensions, military spending, and so on); the emphasis given to these objectives also varies considerably from one country to another. Applying the precautionary principle does not offer an immediate solution, because high costs have to be weighed against risks which are to some extent still unknown. This raises the paradox of trying to estimate the unknown. The precautionary principle can therefore not provide an answer to the question of what constitutes a sensible mix of emission reductions and adaptation. The lack of an optimum policy mix also implies that the principle of intergenerational burden-sharing does not offer a firm basis for a solution. 


\section{No effective policy to date}

The European Union (EU) decided in 1996 that the increase in global temperatures as a consequence of climate change had to be limited in the present century to $2{ }^{\circ} \mathrm{C}$ relative to pre-industrial levels. This position was reaffirmed in 2005, when it was also stipulated that the attainability of the reduction targets should be reviewed in the light of costs/benefits aspects. The EU has a well-developed emissions trading system, putting it at the head of the field. At the same time, the EU pursues a specific climate policy on various fronts. The Netherlands has played a pioneering role in this climate policy. At global level, under the Kyoto protocol the signatory countries agreed to reduce their greenhouse gas emissions in the period 2008-2012 to at least 5\% below the level in 1990. The policy pursued thus far has not proved effective, either in the EU or globally. On the contrary, policy activism in the EU has led to fragmentation, and in the Netherlands to a plethora of changes of direction. The potential for cost-effective domestic climate policy appears to be limited, and much of the effort will therefore have to be directed towards achieving objectives outside the Netherlands (and even outside Europe). Globally, the targets set by the Kyoto protocol are too limited, cover a very short period and apply only for a select group of developed countries which already have relatively $\mathrm{CO}_{2}$-efficient economies. The policy to date - both globally and at the level of the EU and the Netherlands - lacks a global, long-term perspective.

\section{A new climate strategy}

This WRR report sets out a climate strategy which provides both a rationale and direction to the Dutch policy within the EU and to the EU policy in a global context. The Council took the following question as its starting point:

How can the Netherlands, as a member of the European Union, pursue an effective climate policy from a global and strategic perspective?

Key notions which characterise this strategy are: a global and long-term approach as inalienable principles; effectiveness of emission reduction by 2050 ; cost minimisation in the choice between options available now and the choice between options over a period of decades; damage limitation through timely adaptation to a climate which is undeniably changing; unflagging and energetic promotion of low-emission technology and innovation; a strategic approach to global coordination; and finally robustness, in view of the major uncertainties. The proposed climate strategy is based on three policy tracks: (1) adaptation to climate change; (2) reduction of greenhouse gas emissions; and (3) effective global coordination.

\section{(1) High priority for adaptation}

Adapting to a changing climate can reduce or prevent later damage. While adaptation policy cannot and must not replace internationally coordinated reductions in greenhouse gas emissions, for many countries - and in any event for the Netherlands - it is considerably easier to achieve. It is not an acceptance of defeat, but is in fact an attractive option because the fruits of local efforts are also enjoyed locally, something which 
applies to only a very limited extent for emission reductions. Adaptation is not always possible globally, or can be so costly and disruptive that ultimately total emigration becomes unavoidable in certain localities. Adaptation can therefore not be viewed at the purely local level in all cases. The world community can reinforce or supplement the adaptive capacity of poor countries, and will sooner or later have to address vulnerabilities that can threaten the existence or cohesion of entire regions or peoples. For the Netherlands, the most relevant climate changes from a policy perspective are the prospect of a wetter climate and higher sea levels $(+20 \mathrm{~cm}$ to $+110 \mathrm{~cm}$ by 2100$)$. In the first place, therefore, adaptation will be focused on water policy in relation to flood protection; this is of great importance for four reasons:

- Climate change will still occur if emission reductions are successful, albeit in milder form.

- The credibility of coordinated global emission reductions is (so far) low.

- Successful adaptation will improve the Netherlands' international negotiating position.

- Catching up in the area of cost-effective flood protection.

In addition to attention for flood protection, consideration also needs to be given to natural assets and ecology. Climate change not only brings threats to the natural landscape, but also opportunities, and to some extent these opportunities can be created in the wake of the measures taken. Synergy can often be found between flood protection and housing construction or natural recovery. This synergy can be exploited to broaden the support for adaptive measures. The main concern in Dutch adaptation policy is to keep options open. Flood protection measures demand major investments and are long-term in nature. A phased approach could be chosen for these investments; however, the same cannot be said for the creation of space for storing any surplus river water, when it is not certain whether these reserves will ever be used. There are three further problems: first, developed areas cannot be de-urbanised, or at least only at extremely high cost; second, there is insufficient administrative impetus to push through the reservation of space; and thirdly, public support for measures to protect against the flood risk is low. Flood protection is a national interest which needs to be fitted into the local context by seeking optimum solutions, not by watering down the national objectives. In some localities water will need to be given priority over construction, and vice versa. A higher priority for water management requires the adoption of a stronger position by national government, overriding the position of lower administrative echelons. The importance of the flood protection offered by the primary flood barriers will benefit from a greater awareness of the flood risk.

\section{(2) Reduction of emissions: routes and timeframes}

In order to achieve the EU's $2^{\circ} \mathrm{C}$ target, a considerable reduction in global greenhouse gas emissions will have to be accomplished in the coming decades, of the order of 10 11 gigatonnes of carbon (GtC) per year in 2050 compared with a 'business as usual' scenario. The fuels to be used play a decisive role here. There is no time to wait for a 
transition in the energy system; for the moment existing, mature technologies must be used. Modern renewable energy sources (solar, wind, hydropower and modern biomass) offer too little potential to realise a globally adequate reduction in greenhouse gas emissions in the period up to 2030, quite apart from the question of relative costs. Hence, fossil fuels will continue to dominate the world energy supply until at least 2050. Coal in particular will continue to play an important role. A dozen coalbased economies, which together account for roughly two-thirds of the world population, will undoubtedly exploit the existing cheap and well-distributed coal reserves. Thus, a global climate strategy will inevitably have to focus its emission reduction efforts on coal ('clean fossil energy').

- Energy efficiency (3.4 GtC per year). This option saves fuel (often referred to as a 'no regret' option) and is therefore attractive, but this does not mean it comes without cost. The emphasis will have to be placed on electricity consumption, electricity generation and heating. The greatest savings are to be made in the emerging economies.

- Energy mix (4 GtC per year). This route entails $\mathrm{CO}_{2}$ sequestration and storage in combination with gasification technology and the use of biomass. The transport sector could make a significant contribution to this in the longer term, among other things by using biofuels.

- Photosynthesis (2 GtC per year). This route entails the curbing of deforestation, an acceleration in afforestation and reforestation, better utilisation of timber in products and buildings, and more sustainable agriculture. The potential of this option is of limited duration.

- Reduction of other greenhouse gases (1 GtC per year), primarily methane and (industrial) $\mathrm{N}_{2} \mathrm{O}$.

In addition to these main routes, there are additional options for reducing emissions, by means of nuclear energy and wind energy.

The emission reduction routes use mature technology, but are not enough to achieve the further emission reductions that will still be needed after 2050. By that time, the energy supply will have to undergo a transition to emission-free energy. This can only be realized if the wealthy nations invest in large-scale and long-term research and development. The Council recommends the establishment of a Top Technology Institute on emission-free energy for the development of this knowledge. Precisely because of the discrepancy between the existing and desired technology, a clear distinction needs to be made between technology development and technology diffusion. In the present policy of the EU and the Netherlands this distinction is not adequately made, and this in turn pushes up costs.

\section{(3) Effective global coordination}

The greatest task in the coming decades is to ensure that industrialising and poor countries realise their economic growth in an emission-efficient way. The marginal 
costs of emission reduction will remain low in these developing countries for several decades to come, but the reduction in $\mathrm{CO}_{2}$ emissions will only be achieved if the wealthy OECD countries meet all or part of the costs. The Council therefore is of the view that the Netherlands needs to focus its emission reduction efforts as a priority on the Clean Development Mechanism (CDM), if necessary in combination with development policy. The emissions trading system set out under the Kyoto protocol is a valuable instrument for the leading countries, but suffers from the effectiveness paradox: what is achievable is not effective, what is effective is not achievable. The small group of participating countries cannot develop an effective global policy without the countries which do not or are not willing to participate in Kyoto in the foreseeable future. Often, the reluctance of non-participating countries is based on fears of reduced economic growth and a desire to secure energy supplies. This means that, in addition to the Kyoto approach, a 'multicoloured flexibility' is needed in the array of initiatives designed to meet the interests of these countries. This will make it easier to generate support for the development of technologies which facilitate the climate-friendly exploitation of coal than for the setting of emission ceilings which could put a brake on the economic growth of emerging economies. When it comes to energy efficiency, the interests of the climate and of a secure energy supply are parallel, making energy efficiency a promising policy. Common interests form the starting point for the establishment of coalitions which will tackle whole or partial problems jointly. These coalitions could focus on different domains, and could for example consist of coalitions of countries (e.g. heavy polluters which together can have a decisive influence on emissions), as well as corporate coalitions (e.g. companies which agree a joint sectoral standard for energy efficiency in the market, which can be tightened up further as time progresses). The required 'multicoloured flexibility' can take on divergent various forms, varying from a 'no-regret' policy (with enormous potential in developing countries), a 'nolose' policy (which provides incentives to reduce emissions but imposes no sanctions if they are exceeded), technology development and diffusion and intensity targets, to self-imposed climate policy involving accountability and an emissions trading system or carbon price. As with the trade policy, it is both possible and attractive in some areas to stimulate emission reductions bilaterally and regionally, for example as part of existing special relations or development policy. In addition industry, knowledge institutions and NGOS need to be actively in volved in climate policy. Interesting developments are going on at this more horizontal transnational level which should be encouraged where possible.

The United Nations Framework Convention on Climate Change (UNFCCC) offers a suitable framework for multilateral coordination, but in order to make the coordination more effective, a World Climate Organisation (WCO) needs to be set up, as a permanent organisation backed by permanent diplomatic missions. This is necessary in order to create a degree of problem-ownership, so that decisions are taken and implemented. The WCO would need to create an executive body (Special Climate 
Council) for permanent and rotating national members, with a gradual increase in its powers. The WCO could then in time take over the leadership from the de EU, which also implies that the EU and Japan would then no longer be setting (or be able to set) the agenda. Until then, leadership by the EU is both desirable and necessary in order for it to play a catalytic role. 


\section{I NTRODUCTION}

This document is an abridged version of the Dutch-language report on climate policy Klimaatbeleid - tussen ambitie en realisme ('Climate policy - between ambition and realism') published by the Netherlands Scientific Council for Government Policy (WRR 2006). As well as being longer, the original report also contains 12 appendices each focusing in more detail on a specific topic.

\subsection{THE CLI MATE PROBLEM}

The Earth's climate will become warmer in the coming centuries, and the consequences of this will vary widely at local level. This global climate change is due at least in part to human activity. The sustainability of the Earth in the long term depends on a stable atmospheric concentration of greenhouse gases. In order to achieve that stable situation, emissions will have to be brought far below their current levels. The desirability of achieving this reduction forms the starting point for climate policy.

In the longer term, the climate problem is related principally to emissions of carbon dioxide $\left(\mathrm{CO}_{2}\right)$ as a consequence of energy consumption, though the impact of other greenhouse gases such as methane will certainly not be negligible in the shorter term. According to the International Energy Agency, $\mathrm{CO}_{2}$ emissions per head of the global population amounted to 3.9 tonnes per year in 2001 . However, there are considerable differences at national level: per capita emissions in the developed countries average 11 tonnes per year, and in the United States (US) the figure is no less than 19 tonnes. At present, the emissions in poor nations amount to less than 1 tonne per year per head of the population.

The greenhouse effect is associated with wealth and prosperity in two ways. On the one hand increasing prosperity leads to greater consumption of energy and thus to a bigger greenhouse effect. On the other hand, prosperity creates a better balance between gross domestic product (GDP) and energy consumption; in other words, to the extent that $\mathrm{CO}_{2}$ is regarded as pollution, richer countries produce more cleanly than poor countries. The first effect dominates at present. In the near future, the way in which the problem develops will be determined mainly by emerging economies such as India and China.

\subsection{CLIMATE POLICY}

Climate policy has been pursued since the early 1990s. It is based on the 1992 United Nations Framework Convention on Climate Change and, as regards the $\mathrm{CO}_{2}$ emission reductions agreed by the developed countries, on the 1997 Kyoto Protocol, under 
which the signatory countries agreed to reduce their greenhouse gas emissions in the period 2008-2012 to an average of 5 percent below their level in 1990. Although the body of knowledge is increasing, there are still many uncertainties regarding the nature of the climate problem. The accumulation of greenhouse gases in the atmosphere over many decades could however ultimately have such a destabilising impact that a 'no policy' option must be regarded as reckless. The consequences vary widely for different countries.

The policy pursued thus far has not been effective. The objectives in the Kyoto Protocol are focused on the ultra-short term in climatic terms, are not very ambitious in their substance and have no mandatory force in the post-Kyoto period after 2012 . The Kyoto model cannot provide the ultimate solution because efficacy and feasibility are mutually exclusive. The Kyoto instruments serve a useful purpose as precursors, but suffer from a lack of global support needed for their far-reaching implementation.

A strategic climate policy must be based on a long-term approach which is robust enough to deal with the uncertainties that surround the climate problem. A 'robust' approach means a strategy which delivers good results for the climate in a range of future scenarios based on different assumptions.

\subsection{QUESTIONS ADDRESSED IN THE REPORT}

This report seeks to answer the question of how the Netherlands, as a member state of the European Union, can pursue an effective climate policy based on a global and strategic perspective. Without this global perspective, every climate policy is doomed to failure. Achieving an effective climate policy is difficult, given the long time horizon involved and the extreme complexity of the policy setting. The following aspects contribute to this complexity: (a) the great uncertainties in our knowledge of the climate system; (b) the extreme slowness of the climate system; (c) the global setting; (d) the emphasis on economic growth, especially in the poorer countries, as a result of which emissions are more likely to rise than fall; (e) the highly diverging interests of the different countries; and (f) the difficulty or even impossibility of securing worldwide coordination due to weak or perverse incentives.

From a policy perspective, the climate problem can be divided into three main components, or constituent problems, each of which contributes to the solution of the overall problem:

(1) Adaptation. The climate is changing, and it will continue to do so even if emissions are successfully reduced. Emission reduction will slow down the rate of change and reduce the ultimate temperature increase, but will not prevent climate change. Climate policy will therefore have to comprise a mix of adaptation to change and emission reduction. 
(2) Emission reduction routes. Increasing prosperity means growing energy consumption and, as things stand at present, this means a rise in $\mathrm{CO}_{2}$ emissions. This growth will take place mainly outside the OECD countries. Diffusion of available technology to emerging economies could enable these countries to bypass the historical, energy-inten sive path taken by the West in favour of an economic growth path based on much higher energy efficiency. Emission reduction technologies will therefore need to be suitable for application in emerging economies if a global emission reduction policy is to have any chance of succeeding. But fairly radical innovation will also be needed, because it is apparent that in the longer term transitions to new forms of energy and production will be needed and that there are as yet no silver bullets which can solve the problem at a stroke.

(3) Coordination and negotiation. Markets are not capable of internalising the external effects of emissions adequately. There is thus a need for coordinated policy. This coordination issue can be broken down into three constituent issues:

- Development: roughly three-quarters of the world population live in poor or industrialising nations, which is where most of the economic growth will take place.

- Distribution: countries will have to negotiate a system of cost-sharing which is acceptable for all parties.

- Allocation: the required innovation and diffusion will have to be achieved as efficiently as possible.

The Council is interested not only in the effectiveness of climate policy, but also its efficiency. Effectiveness is concerned chiefly with the question of whether the set goals can be achieved; efficiency is on achieving those goals at the lowest possible cost. Lack of efficiency means that 'things are not being done in the best way', something that can be resolved by choosing cheaper available solutions. Lack of effectiveness highlights a discrepancy between the goal and the available resources: the ambition s have been set too high and need to be adjusted and/or the resources made available are in adequate and need to be increased. Lack of effectiveness can thus also lead to the social question of whether 'the best things are being done': a reappraisal of preferences in which climate is just one element. Reflection on this second question is crucial for a strategy, but is much more difficult than the more technocratic first question.

Adequately tempering climate change is an enormous ambition when translated into actual emission reductions. Ambition needs to go hand-in-hand with realism. Taking the interests of the various players as a basis, and taking those diverse interests seriously, increases the chance of pursuing an effective policy in the imperfect world of international relations. The Council favours a pragmatic approach, since this offers the greatest chance of success. This means that, as far as possible, a moral perspective is avoided.

This report is a policy report. The climate as a physical problem is an object of study for the natural sciences. The Intergovernmental Panel on Climate Change (IPCC) is the plat- 
form on which that knowledge is made available; the WRR has nothing to add in that area.

\subsection{STRUCTURE OF THE REPORT}

Chapter 2 presents essential background knowledge. It discusses the choices that have to be made when formulating climate policy against the backdrop of the prevailing uncertainties. The chapter also summarises the present climate policy of the Netherlands and the European Union (EU).

The remaining chapters of the report explore three policy tracks: (1) adaptation to climate change; (2) emission reductions as a means of tempering climate change; and (3) international coordination to achieve those emission reductions.

Chapter 3 discusses adaptation to a changing climate. From the perspective of adaptation, global climate change is above all a regional problem: although the effects occur everywhere, they are felt at local level and differ from one locality to the next; moreover, the costs of adaptation are borne locally. The approach to adaptation taken in the report is chiefly regional, since the focus of the study is limited to the Dutch (European) position. But adaptation is also a global issue, because the poor nations have insufficient capacity to pursue an effective policy (in time) and supporting them is therefore justified.

Chapter 4 focuses on the global strategic pathways for achieving emission reductions. The perspective adopted here is primarily global, since it obviously makes no difference for the climate where emissions (and their reduction) take place. This chapter explores the magnitude of the global challenge that has to be met, looks at the main emission reduction routes and examines which options can be applied most cost-effectively in which regions.

Chapter 5 is concerned with international coordination. The approach here is again primarily global. The key at global level is to apply the technologies discussed in chapter 4 effectively given the backdrop of the interplay of interests and preferences. Coalition formation and leadership are the central issues here. Suggestions are made for a partial institutionalisation of global coordination in order to lower the transaction costs and promote a favourable outcome for approaches based on problem-ownership.

The report concludes with chapter 6 , which links the global approach described in the chapters on emission reduction routes and coordination to Dutch policy. The conclusion is that Dutch policy will be most effective if it is focused on an intelligent combination of Dutch adaptation and effective global emission reduction and coordination. For a small country like the Netherlands, the key is to combine realpolitik with an ambitious and creative approach. 


\section{PROBLEM DEFINITION AND POLICY}

Section 2.1 describes the present state of knowledge about the climate. Section 2.2 discusses the difficult judgments that have to be made in formulating climate policy. Section 2.3 shows that the climate policy pursued to date can at best be seen as a first step.

\subsection{KNOWLEDGE ABOUT THE CLI MATE}

Our knowledge about the climate and the influence of human activity on it is still incomplete, but is increasing. This report takes as its starting point the scientific insights as set out in the Third Assessment Report (TAR) by the Intergovernmental Panel on Climate Change (IPCC 2001), supplemented by more recent insights both at global level (Levin and Persching 2006) and specifically for the Netherlands (MNP 2005; Rooijers et al. 2004). The current level of knowledge suggests that, without a climate policy, the global temperature will rise in the period to 2100 by an average of between $1.4{ }^{\circ} \mathrm{C}$ and $5.8{ }^{\circ} \mathrm{C}$ compared with 1990 . The average world temperature in 1990 was already $0.6^{\circ} \mathrm{C}$ higher than in 1850 .

The global climate system reacts only very slowly to changes in emission patterns. There is a time lag in the reaction of $\mathrm{CO}_{2}$ concentrations to changes in emission patterns because of the long residence times of greenhouse gases (GHGS) in the atmosphere and because emissions resulting from human activity are small in relation to the total amount of $\mathrm{CO}_{2}$ in the atmosphere. Moreover, the global temperature responds slowly to changes in atmospheric concentrations of greenhouse gases because the change in the energy balance is small in relation to the accumulated warmth. There is thus a double delay in the transition from a 'flow variable' to a 'stock variable', in which the second flow is determined by the initial stock of greenhouse gases. In such a slow system, disturbances have a lasting effect and the end result of changes in emission patterns are seen only after many centuries. Even in the event of a reduction in net emissions, the temperature rise that has begun will continue for a long time. Although the year 2100 is often used as an endpoint for projections, a stable final situation will not have been reached by that year, especially as regards sea levels.

There are two main causes of the margin of uncertainty in projecting the rise in average temperatures. First, there is uncertainty regarding the global increase in greenhouse gas emissions. Energy consumption and the extent to which this is based on fossil fuels plays a key role here, but as well as $\mathrm{CO}_{2}$ there are many other GHGs, of which methane is the most important in volume terms. Energy consumption is largely dictated by the rate of economic growth, especially in developing economies. The IPCC has developed a number of projections which have been translated by scientists into emissions scenarios (see the Special Report on Emissions Scenarios (SRES)). 
The second reason for the margin of error is the uncertainty surrounding the many feedback effects, known as climate sensitivity. As a result, the precise influence of an additional tonne of $\mathrm{CO}_{2}$ in the atmosphere is uncertain. The picture is generally dominated by negative feedback, for the simple reason that systems by their nature tend away from instability. However, the climate is a complex and dynamic system with a host of different quasi-stable states; it could be compared with a canoe, which is in a quasi-stable state both when upright and when capsized. Human influence can push the system towards an alternative stable state, in which the system can then remain for a long time (Alley 2004). It is virtually impossible to predict where the threshold lies that leads to a new stable state, and therefore to forecast whether and when a point of no return will be reached. There are several 'sleeping giants' at play here: processes which, once they have begun, could be difficult or impossible to control (New Scientist, 12 February 2005: 9-11).

The climate problem is at once too large and too small. It is too large in the sense that the consequences in the long term are very considerable and the ability to control those consequences is limited. It is questionable whether, given the present status of technology and international coordination, the climate problem can be resolved at all (in other words, whether the $2^{\circ} \mathrm{C}$ target set by the European Union (EU) is realistic). At the same time, the climate problem is too small in the sense that in the period up to 2050 no genuinely threatening harmful effects are likely to occur. Engendering a sense of urgency generally requires a dramatic event in the short term. The changing climate may make the prospect of such events likely in the long term, but by then it will be much too late to do anything about them. This opposition creates a predicament for those trying to draw the climate problem to the world's attention. In order to prevent policy efforts becoming paralysed, the actions needed in order to resolve the problem are sometimes portrayed as smaller than they are in reality. The other side of the predicament is that, in order to increase people's perception of the problem, tactical and strategic research results are aired which show that climate change is already clearly observable and can/will lead to all manner of apocalyptic scenarios - in which the words 'can', 'will' and 'could' are sometimes used interchangeably.

\subsection{DIFFICULT CHOICES}

\subsubsection{PROBLEMS IN DECIDING BETWEEN ADAPTATION AND EMISSION REDUCTION}

From a purely economic point of view, the ideal would be an optimum mix between adaptation policy and emission reduction policy. This optimum mix could be found by equalising the marginal costs of emission reduction and adaptation (both in a broad sense). However, this is possible only in theory; practical reality is a different matter. In the climate debate the urgency of the need for emission reduction policy is argued 
on the basis of adaptation costs and uncertainty. This can create the false impression that, rather than following an analytical, logical path that results in an estimation of effects based on the actions to be undertaken, the opposite path is in fact being followed, which starts from a preference for certain actions and leads to a justification of that preference through an estimation of the effects. The weighing up of the costs of adaptation and emission reduction is thus be hedged in with a number of taboos in practice. Here, the discussion is focused on whether it is possible to formulate an optimum global climate policy. The discussion is abstracted from regional differences in costs of adaptation and emission reduction, and from the question of whether an optimum global climate policy could actually be implemented via negotiation.

Many studies suggest that adaptation policy is a necessary complement to an emission reduction policy, because climate change cannot be avoided entirely, but that adaptation policy cannot replace emission reduction policy (IPCC 2001 ; Easterling et al. 2004; VROM-raad and AER 2004). The implicit priority this gives to emission reduction policy over adaptation policy is something that demands critical reflection.

When seeking an optimum mix between adaptation policy and emission reduction policy, a distinction has to be made between cost-effectiveness on the one hand and a cost-benefit analysis on the other. In analyses relating to cost-effectiveness the goal is fixed (in this case a temperature increase of less than $2{ }^{\circ} \mathrm{C}$ ) and this goal is achieved with the deployment of the fewest resources possible. Typically, the goal is measured using different criteria from the resources. In a cost-benefit analysis, the goal is derived from the costs to be incurred and the anticipated benefits. The marginal benefits of emission reduction policy (= emission reduction benefits) consist in the avoided damage due to climate change and consequently the saved adaptation costs, possibly reduced by the unrealised benefits of climate change. For the first tonne of $\mathrm{CO}_{2}$ equivalents, the emission reduction costs are low and the emission reduction benefits are high; for the last tonne the reverse applies. The optimum goal is reached when the marginal emission reduction costs are equal to the marginal emission reduction benefits. It is therefore essential that the costs and benefits can be measured using the same (euro)criteria.

However, there are four fundamental problems in making these judgments: (1) uncertainty makes it difficult to estimate the probability of extreme events and the costs of solution options; (2) it is unclear how the costs of adaptation should be valued and how the distribution question influences the valuation of emission reduction costs; (3) emission reduction costs and adaptation costs are difficult to compare, because they are evaluated on completely different time horizons; (4) it should be possible to solve the third problem by applying a conversion factor, but unfortunately conversion factors are found to be the output rather than the input of the judgment. 


\subsubsection{THE PRECAUTIONARY PRINCIPLE AS AN ANSWER TO UNCERTAI NTY}

The precautionary principle is often hailed as the solution to problems where there are great uncertainties, but it is not a panacea. A balance has to be struck between the risk that lobbies which are in danger of losing out if far-reaching measures are taken will irresponsibly call for deferment of those measures, and the risk that unjustified investments will be made based on unfounded fears. In short, precaution cannot replace judgment. The European Commission (2000) has laid down this argument in the proportionality principle.

In order to enable judgments to be made as well as possible in this atmosphere of uncertainty, a distinction has to be made between risk and uncertainty and between prevention and precaution. Risk and uncertainty are different concepts. Risk is stochastic, while uncertainty refers to a lack of knowledge which may become available at a later time. There may be uncertainty about risks, i.e. incomplete knowledge about the stochastic distribution of possible outcomes. Similarly, prevention and precaution are different concepts. In essence, prevention is about management of known risks, a judgment between the marginal costs and benefits of prevention. Precaution, by contrast, is about managing lack of knowledge. If precaution were to be interpreted as prevention, there would be no difference from the perspective of risk assessment between the precautionary principle and traditional risk management. The point of departure for the precautionary principle is that where there is uncertainty about risks for the environment or health, for example, it is not appropriate to wait for complete proof before taking action. The precautionary principle thus becomes relevant as soon as it seems likely that more knowledge will become available in future about the optimum risk management. Waiting for that knowledge can be both a right and a wrong strategy. The crucial question is which uncertainties justify which actions.

The precautionary principle is not designed to prevent risks, but is much more about selecting a policy line that is robust in a range of scenarios - not only extreme scenarios, but also a scenario in which all efforts fail to produce results. Precaution is about the timing of decisions in the light of developing knowledge.

\subsubsection{ETHICAL CONSI DERATIONS}

Most actions cannot be argued rationally, because preferences and choices are driven by value judgements and are diverse. Adistinction can be made here between morals and ethics (Reiss and Straughan 2001). Morals refer to the moral views, ideas and beliefs that form the basis for an assessment of what an individual feels is right or wrong. Ethics are a tool to enable preferences to be weighed up in a reasoned way even where there are divergent moral views. Ethical judgements are therefore never defi- 
nitive or provable, because the moral judgments on which they are based are also not definitive or provable. Ethics are therefore a method for achieving consensus in the midst of diverging preferences and interests, but are not a recipe for a solution. The appreciation of climate change is not the same everywhere, and this also applies for moral views on norms and responsibilities. This is partly because of regional differences in the consequences of climate change, but also because regions or countries apply different priorities and have different cultures. Convergence may occur, but it equally may not.

The notion of justice is based on more or less universal norms; fairness is slightly less pretentious because it takes into account a weighing of interests. Both justice and responsibility demand a participative approach. Virtually every sharing of costs can be defended by a particular interpretation of fairness principles, on a continuum whose extremes are the principle of 'grandfathering' (where rights are allocated on the basis of the status quo) and the principle of an equal distribution of emission rights per head of the world population (Rose and Stevens 1998). Ultimately the sharing of costs is based on a negotiation result: the concept of 'negotiated justice'. The negotiation result can take account of several interpretations at one and the same time, for example due to a gradual shift in the relative weight of principles: tying into the present by assigning weight to the status quo and gradually shifting to an increasing focus on the future through equal emission rights, with the negotiation result determining the path along which this shift takes place.

The negotiation result must be capable of interpretation in terms of fairness. There is a degree of consensus concerning the minimal conditions which a fairness argument must meet if it is to be acceptable: need (the need for socioeconomic development to ensure that basic human needs are first met), capacity (the economic and technological resources to contribute to solving the problem) and responsibility (contribution to the cause of the problem) are in any event essential ingredients (Höhne et al. 2003), but these ingredients can be combined to produce very different recipes. The principle adopted in the United Nations Framework Convention on Climate Change (UNFCCC), of common but differentiated responsibilities, is gradually being defined in more concrete terms in the successive Conferences of the Parties (COP).

In conclusion, widely diverging position s can be defended from an ethical perspective. Ethical approaches are fruitful where they offer a common platform enabling parties to reach agreement, but they are counter-productive and drive parties apart if they break down into accusations about unethical behaviour. In a heterogeneous environment it is better to take mutual interests and the possibilities for achieving mutual benefit as a starting point. Where it may be desirable from the point of view of justice and fairness to adopt the principle of 'the polluter pays', the harsh reality is that it is often the party that suffers damage which finds itself forced to pay. 


\subsubsection{THE POLITICAL DECISION-MAKING PROCESS}

The climate problem is hedged in with many uncertainties. This means that the sense of urgency about the problem is open to manipulation, both in an alarmist and a complacent direction. On the one hand it can be observed that the existence of stakeholders in a problem offers a good guarantee for the continued existence of that problem, or a least the sense of urgency regarding it, especially where governments enter the picture as grant-providers. In the last 20 years a sizeable group of stakeholders in the climate problem has grown up. On the other hand, major economic and political interests are tied up in the pursuit of the emission reduction policy. Energyintensive industries will be confronted with high costs in offsetting external environmental effects, while the political interests are also considerable, because climate policy can stand in the way of economic growth and because factors such as security of energy supply carry great political weight.

In an ideal situation, science would provide knowledge and politicians would deliver a political view. Such a division of tasks does not work optimally in the climate debate, however. Policymakers often lack the knowledge needed for a proper assessment of the scientific basis of research; there is too little acknowledgement that the research sometimes amounts to 'whistling in the dark'. In addition, circular arguments arise, in which a political choice made 'in the dark' is justified by a quasi-technical choice which is in reality itself a political choice. Precisely because the future is so uncertain, there is relatively wide scope for influencing outcomes through the choice of apparently technical growth rates: population growth, rate of economic growth, degree of convergence of economies, changes in the carbon intensity of gdp, and so on. The values chosen for these growth rates have a major and sometimes decisive influence on the outcomes of the calculations.

Additionally, a report by the British House of Lords (2005) identifies an opposing mix of science and politics in the process of the IPCC. Interference by politicians in the tar Summary for policymakers gives rise to contradictions between the scientific base text and the political summary of it. The review process is also not always entirely smooth. The House of Lords report also points out that there is in any event a sense that ideology plays a role in the appointment of IPCC members. Consciously or unconsciously, the margin of uncertainty is used to turn the analyses on their heads, not from empiricism to policy, but from policy to empiricism.

In order to maintain public confidence in the IPCC and the urgency of the need for climate policy, it is essential to set the highest possible standards in terms of impartiality and scientific objectivity. Knowledge does not arise as a result of political consensus, but through free discussion and solid empirical research. 


\subsection{POLI CY PROGRESS TO DATE}

\subsubsection{THE POSITION OF THE EU}

\section{Goals}

In terms of giving a lead, the EU has adopted a clear position, though one which is gradually shifting under the influence of developments in knowledge and international relations. At the 1.939th meeting on the environment in Luxembourg (1996), the Council of Ministers of the EU expressed the following opinion:

"Given the serious risk of such an increase and particularly the very high rate of change, the Council believes that global average temperatures should not exceed 2 degrees above pre-industrial level and that therefore concentration levels lower than $550 \mathrm{ppm} \mathrm{CO}_{2}$ should guide global limitation and reduction efforts."

The EU position makes no explicit judgment between the expressed wish and the efforts needed to fulfil it. There is a lack of proportionality between the risk that gives rise to the appeal to the precautionary principle on the one hand, and the efforts needed to reduce that risk on the other. The European Commission has however indicated that it considers this proportionality to be desirable (European Commission 2000). At the summit of 23 March 2005 (7619/05), the Council reaffirmed the $2{ }^{\circ} \mathrm{C}$ target was confirmed and gave a commitment to a strategy and emission reduction target for the period between 2012 and 2020, though for the former the Council also stipulated that the reduction targets had to be feasible taking into account the costs and benefits.

\section{Instruments}

The instruments of EU climate policy form an integral part of EU environmental policy. The emissions trading system is a core element of the climate policy; it is a thoroughly worked out system which serves as an example to the rest of the world. For its effectiveness, however, this system requires more stringent reduction targets than those that set under the Kyoto Protocol. Figure 2.1 illustrates that specific policy is also pursued focusing on energy and energy conservation, industry and transport. 
Figure 2.1 Current EU climate policy

\section{Transport}

- See also 2001 Sustainable Transport Strategy

- Intermodal shifts

- liberalisation/reforms (EU railways)

- river and coastal navigation

- intermodality

- Economic system, levies for use of infrastructure

- EU bandwidths for excise duty on fuels

- Selective: tax exemptions for fuels

(e..g.. bio); tax breaks for hybrid cars

- Minimal share taken by biofuels

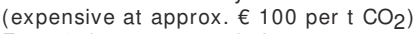

- Euro-4; i now proposals for euro-5 (diesel and other standards) (cobenefits)

- EU covenant, voluntary reduction in $\mathrm{CO}_{2}$ by automotive industry
Kyoto and emissions trading

- Ratification in 2002

- Monitoring/measurement systems

- Specific measures (see rest of figure)

- Emissions trading system

- internal (EU-25 + EER)

- linking the directive on credits JI + CDM

- (2008), IET trading with Canada, Japan etc.)

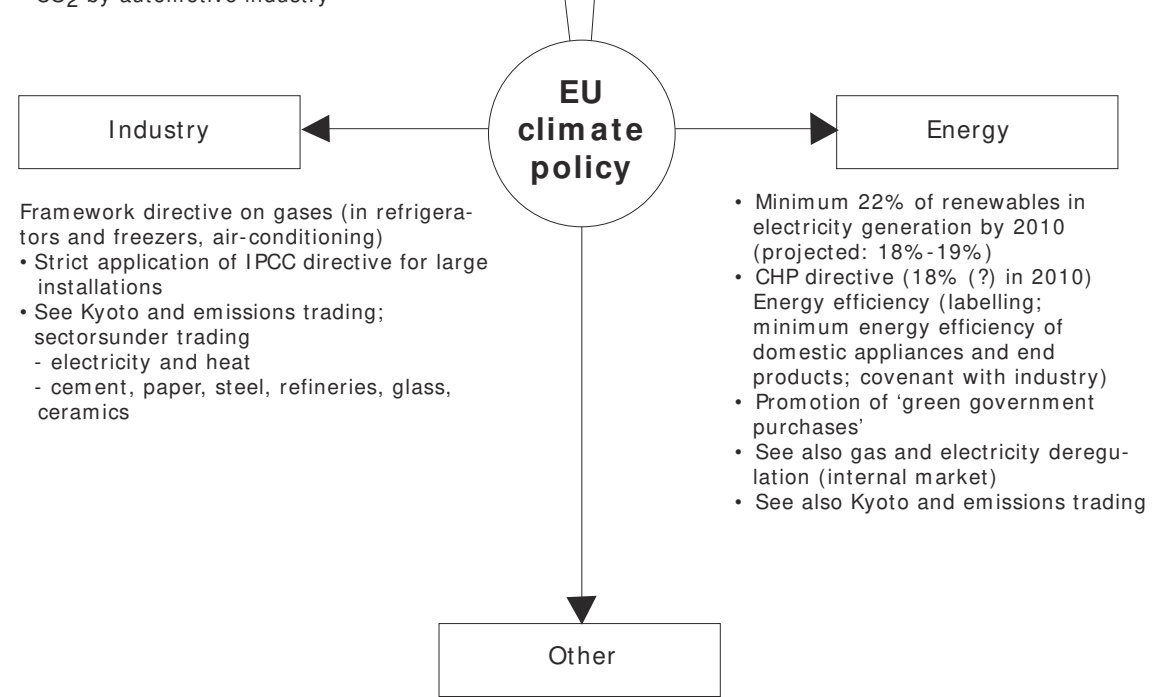

- Energy saving in buildings, directive

- See reform of agricultural policy (cross-compliance)

- Landfill directive (reducing methane from waste)

- Climate research programmes

- Technology programmes, technology platforms (e.g. hydrogen), international partnerships (e.g. methane, CCS, nuclear energy, nuclear fission - ITER)

- Beginning attention for adaptation 


\subsubsection{DUTCH POLICY}

The Netherlands has played a pioneering role in climate policy. Policy activism has however led to a fragmented, technically complex and continually changing policy. The Kyoto approach appears to have been laid over the top of this as an 'extra policy layer'. Moreover, the policy has changed due to correction of cost-ineffective policy, especially where this resulted in budgetary problems.

Figure 2.2 summarises present Dutch climate policy. Typical of that policy is the wide use of 'covenants', sometimes stand-alone, sometimes in conjunction with general policy (e.g. fiscal policy), or specific policy (e.g. standards or grants). Sizeable subsidies have been deployed in specific areas, such as the environmental quality of electricity generation (MEP) and energy investment allowances (EIA), though sometimes these subsidies are also so minimal (e.g. freight transport) that the transaction costs are likely to be high compared with the effect achieved. The emission reduction potential within the Netherlands is limited; the Netherlands is already fairly $\mathrm{CO}_{2}$-efficient (Ministry of Economic Affairs 2005). 
Figure 2.2 Present Dutch climate policy

\begin{tabular}{|c|c|}
\hline Transport & Kyoto and emissions trading \\
\hline $\begin{array}{l}\text { - Promotion of technically efficient fuel } \\
\text { consumption } \\
\text { - car labelling } \\
\text { - (small) subsidies for freight transport } \\
\text { - rebate for fuel-efficient cars } \\
\text { - (Mild) behaviour or campaigns } \\
\text { - Implementation of EU directive on } \\
\text { biofuels } \\
\text { - EU automotive industry covenant } \\
\text { - IEA (see Industry) } \\
\text { - Vary tax with fuel-efficiency; and } \\
\text { hybrid/H2 car zero }\end{array}$ & $\begin{array}{l}\text { - Allocation October } 2004 ; 206 \text { plants; } \\
\text { opt-out for } 93 \text { plants } \\
\text { - National register, summer } 2005 \\
\text { - NEa, with 'monitoring protocols' } \\
\text { - Trading since early } 2005 \\
\text { - Fairly low domestic emission reduction } \\
\text { ratio (external) em ission reduction } \\
\text { projects foreseen for } 2010\end{array}$ \\
\hline Industry & Energy \\
\hline $\begin{array}{l}\text { - Covenants } \\
\text { - benchmark efficiency (energy-intensive } \\
\text { businesses among world's best for } \\
\text { energy efficiency) } \\
\text { - mixed policy for non-energy-intensive } \\
\text { industry, } \\
\text { - aluminium (PFCs and } \mathrm{CO}_{2} \text { reduction) } \\
\text { - Energy investment allowance for innova- } \\
\text { tive energy technologies (IEA) } \\
\text { - N20 reduction (e.g. fertilisers), HFCs, and } \\
\text { PFCs - voluntary + ceilings } \\
\text { - (See also emissions trading; in } 2010 \text { only } \\
0.3 \mathrm{Mt} \mathrm{CO}_{2} \text { avoided) }\end{array}$ & $\begin{array}{l}\text { - Covenants } \\
\text { - reduced methane emissions } \\
\text { (oil/gas producers) (success)) } \\
\text { - biomass (coal covenant) } \\
\text { - wind (agreed with provinces) } \\
\text { - benchmark efficiency (see } \\
\text { Industry) } \\
\text { - Grants (MEP), up to } 10 \text { years } \\
\text { - renewables } \\
\text { - CHP } \\
\text { - (See also emissions trading; } 2010 \\
\text { only } 1.1 \mathrm{Mt} \mathrm{CO}_{2} \text { avoided) }\end{array}$ \\
\hline General (not sectoral) & \\
\hline $\begin{array}{l}\text { - Fiscal } \\
\text { - energy investment allowance (EIA) } \\
\text { - green taxes } \\
\text { - Subsidies, director GHG reduction } \\
\text { - CO2, major investment projects } \\
\text { - OGG reduction (+ tax allowances) in } \\
14 \text { projects } \\
\text { - Covenants (see sector, given main } \\
\text { effects) }\end{array}$ & $\begin{array}{l}\text { - Agriculture } \\
\text { - horticulture covenant (efficient energy } \\
\text { up to 2010) } \\
\text { - NOx and methane fire fertiliser and } \\
\text { livestock policy } \\
\text { - Forestry, small extra acreage } \\
\text { - Waste } \\
\text { - waste reduction, sharp reduction in } \\
\text { methane emissions } \\
\text { - energy from waste } \\
\text { - Built-up environment } \\
\text { - mixed policy for housing } \\
\text { - energy consumption norms for } \\
\text { offices/factories; falling since } 1995 \\
\text { - EPR (with renewables) stopped (fairly } \\
\text { expensive) } \\
\text { - energiebelasting, om hoog sinds } 1996\end{array}$ \\
\hline
\end{tabular}

Source: VROM (2005) 


\section{ADAPTING TO A CHANGING CLI MATE}

\subsection{NTRODUCTION}

The climate is changing inexorably. Given the international diversity of interests and priorities, there is a real risk that an internationally coordinated greenhouse gas policy will fail to get off the ground, or at least to an adequate degree; we shall look at this in more detail in the following chapters. But even if these efforts are successful, emission reductions cannot halt the warming up of the Earth. Adaptation to a changing climate will therefore be necessary whatever happens.

From the point of view of adaptation, climate change is a regional problem: its effects occur everywhere, but they are felt locally and differ from one locality to the next. The fruits of adaptation efforts are also enjoyed at local level. Mobilising stakeholders is therefore easier than with a greenhouse gas policy, which requires international coordination in order to curb the 'free rider' effect. On the other hand, the costs of adaptation can vary widely at local level; A (Dutch or European) policy to distribute these costs fairly therefore demands a degree of international coordination.

This chapter is built up as follows. Section 3.2 summarises both the global and Dutch adaptation agendas from the perspective of policy relevance. These summaries show that the relevant adaptation issues relate mainly to water management. Adaptation measures in relation to water management place demands on the already scarce space; this is the subject of section 3.3. In the light of this, these measures are weighed against other spatial functions. In addition to a technical problem, therefore, there is also an administrative problem; this is the subject of section 3.4.

\subsection{THE POLICY AGENDA FOR ADAPTATION}

\section{Global consequences of climate change}

The consequences of climate change will probably become greater as the rise in global temperatures progresses. Those consequences are expected to show regional variation. Hitz and Smith (2004) bring together the results of a large number of studies on climate change; most studies of the consequences of climate change leave unanswered the question of whether the influence of climate change dominates. The extraction of natural resources by human beings also generally has far-reaching consequences for the natural environment. Some of the problems that could result from climate change are thus not new.

In general, the studies show that the $2{ }^{\circ} \mathrm{C}$ limit set by the European Union (EU), which is accepted as a guideline for policy, need not necessarily be the temperature increase 
at which negative effects begin to dominate; higher temperature rises are also cited. The following consequences of climate change emerge in each focus area:

- Hazards that threaten coastal areas include more flooding due to increased sea levels and a greater risk of storms, together with silting up of the surface water.

- The agricultural potential, especially for cereals, will increase if there is a limited temperature increase of approximately $3-4{ }^{\circ} \mathrm{C}$. The famine problem is related only in the final instance to agricultural output; much more important are the availability of work for the poor and the organisation of world trade.

- Wide regional differences are predicted in changes in the availability of water. On balance, little can be said about the availability of water as a result of global warming. A world agricultural market could largely accommodate the consequences of changes in the availability of water.

- Theoretically, global warming could foster the spread of diseases such as malaria. However, there are many ways of halting the spread of such diseases, which are primarily a result of poverty.

- Leemans and Eickhout (2004) expect future climate change to have a major impact on existing ecosystems. They do however see differences in the ability to adapt. Changes in the climate generally take place at the expense of the wealth of species. The more rapid the changes, the greater the consequences. The most afforested ecosystems, it is argued, are capable of adapting to a temperature change of only $0.05{ }^{\circ} \mathrm{C}$ per decade.

\section{Why should the Netherlands adapt?}

The Netherlands Environmental Assessment Agency (MNP 2005) has compiled an extensive inventory of the effects of climate change in the Netherlands. Table 3.1 is based on this inventory, though the final four columns are a policy-specific interpretation of the report. For the government, adaptation issues are only relevant if policy can make a difference. This question is answered broadly in four steps in table 3.1. The focus is more on the method than the actual valuation, which is in any event to some extent a value judgment and therefore open to discussion.

The first two questions are concerned with evaluating the consequences of climate change. A monetary measure has been chosen for this, without this implying that only the financial consequences have been counted. Consequences are only relevant for policy if they can be reduced or prevented with adaptation policy. The costs of that policy must be in proportion to the monetary magnitude of the consequences; this means that small consequences are also worth specific policy provided that policy is cost-effective. The final question looks at the added value of preventive policy. The consequences of climate change become visible only in the relatively long term; if something is to be done about this now, preventive policy must have added value compared with reactive policy at some point in the future. If there is no point in prevention, but the policy will later have added value, policy today is at best worthwhile as a way of building up a budgetary reserve. 
Table 3.1 shows that after answering the above four questions, the problems in relation to water management stand out as an issue with major consequences and high added value for preventive policy. For this reason, the rest of this chapter focuses on water policy. This does not mean that water policy is the only relevant topic; there are for example problems associated with the investment cycle, in which preventive policy has clear added value. Nonetheless, those problems are not discussed further in this chapter, since when highlighting such problems the solution becomes more or less obvious. 
Table 3.1 Effects of climate change ${ }^{1}$

\begin{tabular}{|c|c|c|}
\hline \multirow[t]{2}{*}{ Cause } & \multicolumn{2}{|c|}{ Physical change } \\
\hline & Sector & Consequences now (vs. pre-industrial) \\
\hline \multicolumn{3}{|l|}{ Temperature } \\
\hline \multirow[t]{5}{*}{ Average } & \multicolumn{2}{|c|}{ Now $+1{ }^{\circ} \mathrm{C}$, rising to maximum $+6{ }^{\circ} \mathrm{C}$} \\
\hline & Nature & $\begin{array}{l}\text { Northward relocation of species, increase in seven and } \\
\text { generally occurring species, decline in northern and specific } \\
\text { species }\end{array}$ \\
\hline & Health & Probable decline in gen. average relative mortality \\
\hline & Agriculture & Diseases/pests: more common \\
\hline & Health & Malaria in the Netherlands \\
\hline \multirow[t]{2}{*}{ Extreme, heat } & \multicolumn{2}{|c|}{ Now $3 x$ as many hot days, further increase in severity and frequency later } \\
\hline & Health & Increase in relative mortality in hot periods \\
\hline \multirow[t]{4}{*}{ Extreme, cold } & \multicolumn{2}{|c|}{ Now half as many cold days, falling trend } \\
\hline & Tourism & $\begin{array}{l}\text { Reduced ice-skating opportunities, less chance of Elfsteden- } \\
\text { tocht ice-skating race (though still possible) }\end{array}$ \\
\hline & & Reduced skiing opportunities \\
\hline & \multicolumn{2}{|l|}{ Health } \\
\hline \multirow[t]{5}{*}{ Seasons } & \multicolumn{2}{|c|}{ Longer summer, earlier spring } \\
\hline & Nature & $\begin{array}{l}\text { Ecosystem disruption, e.g. egg-laying dates, appearance of } \\
\text { animals, blooming of spring plants }\end{array}$ \\
\hline & Agriculture & Longer growing season \\
\hline & Tourism & Extended tourist season, more periods with good weather \\
\hline & Health & Lyme disease: tick bites doubled in 10 years \\
\hline \multirow{5}{*}{$\begin{array}{l}\text { Water } \\
\text { temperature }\end{array}$} & \multicolumn{2}{|c|}{ Sea water becomes warmer } \\
\hline & Nature & $\begin{array}{l}\text { Change in plankton population, possible consequences } \\
\text { higher up the food chain. Reduction in shellfish in Wadden } \\
\text { Sea, leading to decline in certain bird species }\end{array}$ \\
\hline & Tourism & Blue algae-related infections \\
\hline & \multicolumn{2}{|c|}{ Rhine temperature now $+3^{\circ} \mathrm{C}$., partly due to climate. Rising under conditions } \\
\hline & Industry & Occasional constraints on take-up of cooling water \\
\hline
\end{tabular}


continued from Table 3.1

\begin{tabular}{|c|c|c|c|c|}
\hline Future consequences & Chance $^{2}$ & $\begin{array}{l}\text { Potential } \\
\text { monetary } \\
\text { consequen- } \\
\operatorname{ces}^{3}\end{array}$ & $\begin{array}{l}\text { Policy } \\
\text { added } \\
\text { value }^{4}\end{array}$ & $\begin{array}{l}\text { Added } \\
\text { value of } \\
\text { preventive } \\
\text { policy } 5\end{array}$ \\
\hline & \multicolumn{4}{|c|}{ Varies with increase } \\
\hline $\begin{array}{l}\text { Further relocation of mobile } \\
\text { species, climate relocation of } \\
400 \mathrm{~km} / \text { century is too rapid for } \\
\text { many ecosystems, reduction in } \\
\text { biodiversity }\end{array}$ & Likely & $\begin{array}{l}\text { Radical, } 6 \text { but } \\
\text { with uncertain- } \\
\text { ty and evalua- } \\
\text { tion problem }\end{array}$ & $\begin{array}{l}\text { Moderate, } \\
\text { EU-scale }\end{array}$ & $\begin{array}{l}\text { Large, } \\
\text { defragmen- } \\
\text { tation }\end{array}$ \\
\hline Continuing development & Very likely & $\begin{array}{l}\text { Limited } \\
\text { (N.B.: positive) }\end{array}$ & Low & Low \\
\hline Greater potential harvest losses & Limited & Limited & Low & Low \\
\hline \multirow[t]{2}{*}{ Ditto } & $\begin{array}{l}\text { Virtually } \\
\text { ruled out }\end{array}$ & Limited & Low & Low \\
\hline & \multicolumn{4}{|l|}{ Very likely } \\
\hline \multirow{2}{*}{$\begin{array}{l}\text { Further increase in heat-related } \\
\text { mortality, limited loss of years } \\
\text { of life }\end{array}$} & Likely & $\begin{array}{l}\text { Limited, with } \\
\text { uncertainty }\end{array}$ & Moderate & Low \\
\hline & \multicolumn{4}{|l|}{ Very likely } \\
\hline $\begin{array}{l}\text { Further decrease in chance of icy } \\
\text { periods (less than proportionate) }\end{array}$ & Very likely & Small & Low & Moderate \\
\hline $\begin{array}{l}\text { Further reduction in skiing season } \\
\text { and area }\end{array}$ & Very likely & Small & Low & Low \\
\hline \multirow[t]{2}{*}{ Fall in cold-related mortality } & Very likely & Small & Low & Low \\
\hline & \multicolumn{4}{|l|}{ Likely } \\
\hline $\begin{array}{l}\text { Further disruption in the food } \\
\text { chain }\end{array}$ & Likely & Limited & Low & Low \\
\hline $\begin{array}{l}\text { Continuing extension; higher } \\
\text { yields; chances for different crops }\end{array}$ & $\begin{array}{l}\text { Virtually } \\
\text { certain }\end{array}$ & $\begin{array}{l}\text { Limited } \\
\text { (N.B.: positive) }\end{array}$ & Low & $\begin{array}{l}\text { Moderate (crop } \\
\text { transitions) }\end{array}$ \\
\hline $\begin{array}{l}\text { Netherlands more attractive } \\
\text { for holidays; Southern Europe } \\
\text { becomes too hot }\end{array}$ & $\begin{array}{l}\text { Virtually } \\
\text { certain }\end{array}$ & $\begin{array}{l}\text { Limited } \\
\text { (N.B.: positive) }\end{array}$ & Low & Low \\
\hline \multirow[t]{2}{*}{ Further increase } & Likely & Small & High & Low \\
\hline & \multicolumn{4}{|l|}{ Likely } \\
\hline $\begin{array}{l}\text { Further shifts with possible step } \\
\text { change in ecosystems }\end{array}$ & Likely & $\begin{array}{l}\text { Small, with } \\
\text { uncertainty }\end{array}$ & Low & Low \\
\hline Further increase & Very likely & Small & Moderate & Low \\
\hline $\begin{array}{l}\text { Considerable chance of } \\
\text { restrictions }\end{array}$ & Very likely & Limited & Moderate & $\begin{array}{l}\text { High, invest- } \\
\text { ment cycle }\end{array}$ \\
\hline
\end{tabular}


continued from Table 3.1

\begin{tabular}{|c|c|}
\hline \multirow[t]{2}{*}{ Cause } & Physical change \\
\hline & $\begin{array}{l}\text { Consequences now } \\
\text { (vs. pre-industrial) }\end{array}$ \\
\hline \multicolumn{2}{|l|}{ Precipitation } \\
\hline $\begin{array}{l}\text { Average } \\
\text { (great variability) }\end{array}$ & $\begin{array}{l}\text { Now approx. } 20 \% \text { more; the relationship between seasons will also } \\
\text { change: summer more, winter less }\end{array}$ \\
\hline \multirow[t]{3}{*}{ Extreme: rainfall } & $\begin{array}{l}\text { Now }>50 \% \text { more days with }>15,20 \text { or } 25 \mathrm{~mm} \text {. This trend will } \\
\text { continue, more days of extreme precipitation }\end{array}$ \\
\hline & More frequent damage \\
\hline & Greater nuisance \\
\hline \multirow[t]{3}{*}{ Extreme, drought } & More dry years and rain shortages, though very variable \\
\hline & More frequent damage \\
\hline & General, drinking water \\
\hline Evaporation (summer) & Proportionate with temperature increase, in $2100+4 \%-16 \%$ \\
\hline Wind & $\begin{array}{l}\text { Reduction in number of storms (since 1962); possibly more } \\
\text { extreme storms in the future }\end{array}$ \\
\hline \multirow[t]{2}{*}{ Rise in sea level } & $\begin{array}{l}\text { Due to melting of land ice, discharge of seawater and soil erosion. } \\
\text { Now }+20 \mathrm{~cm} \text {, expectation is }+10-+45 \mathrm{~cm}(2050) \text { and }+20 \mathrm{~cm}- \\
+110 \mathrm{~cm}(2100) \text {. Uncertain chance of much greater increase }\end{array}$ \\
\hline & Greater flooding risk \\
\hline
\end{tabular}

\begin{tabular}{|c|c|}
\hline \multicolumn{2}{|l|}{ River discharges } \\
\hline \multirow[t]{2}{*}{ Winter } & $\begin{array}{l}\text { Higher norm discharge rate (Rhine from } 15,000 \mathrm{~m} 3 \text { to } 16,000 \mathrm{~m} 3 \text { ), } \\
\text { increase of } 3 \%-10 \% \text { for the Rhine and from } 5 \%-10 \% \text { for the } \\
\text { Meuse in } 2050\end{array}$ \\
\hline & Greater flooding risk \\
\hline \multirow[t]{2}{*}{ Summer } & Average lower discharges, minimum 10\%-50\% lower in 2050 \\
\hline & $\begin{array}{l}\text { Shipping: occasional limitations during } \\
\text { drought }\end{array}$ \\
\hline
\end{tabular}

Water nuisance

IJsselmeer levels

Level slightly increased; this will continue mainly in winter.

Fluctuations increase

Water management

1 This table is a modified copy of a table in 'Effects of Climate Change', Environmental and Nature Planning Agency (Milieu en Natuurplanbureau) 2005, pp. 12-13. The last three columns are our interpretation of the main text in this report.

2 The chance of an effect occurring is conditional, with the physical change referred to as the condition.

For example: a long growing season is virtually certain if a shift takes place in the length of the seasons. However, that shift is anything but certain.

3 The consequences of the realisation of this effect are indicated here in monetarised form. It is not therefore only a matter of damage which is intrinsically monetary in itself. A global division has been chosen using the categories 'small', 'limited', 'sizeable'. The uncertainties surrounding a number of items reflect the uncertainty regarding the value of a change, not the uncertainty as to whether the change will take place (column 'Chance'). 
continued from Table 3.1

\begin{tabular}{|c|c|c|c|c|}
\hline Future consequences & Chance $^{2}$ & $\begin{array}{l}\text { Potential } \\
\text { monetary } \\
\text { conse- } \\
\text { quences }\end{array}$ & $\begin{array}{l}\text { Policy } \\
\text { added } \\
\text { value }^{4}\end{array}$ & $\begin{array}{l}\text { Added value } \\
\text { of preventive } \\
\text { policy } 5\end{array}$ \\
\hline & \multicolumn{4}{|l|}{ Likely } \\
\hline & \multicolumn{4}{|l|}{ Unclear } \\
\hline Continuing development & $\begin{array}{l}\text { Virtually } \\
\text { certain }\end{array}$ & Limited & Moderate & Low \\
\hline Continuing development & $\begin{array}{l}\text { Virtually } \\
\text { certain }\end{array}$ & Limited & Low & $\begin{array}{l}\text { High, invest- } \\
\text { ment cycle, } \\
\text { spatial options }\end{array}$ \\
\hline Continuing development & Very likely & Limited & Moderate & Low \\
\hline \multirow[t]{4}{*}{ Salt intrusion } & Very likely & Limited & Moderate & Low \\
\hline & \multicolumn{4}{|c|}{ Linked to temperature } \\
\hline & \multicolumn{4}{|c|}{ Now: very likely; future: uncertain } \\
\hline & \multicolumn{4}{|c|}{ Now: certain; certainty decreases with time } \\
\hline \multirow[t]{2}{*}{ Increasing further } & $\begin{array}{l}\text { Virtually } \\
\text { certain }\end{array}$ & Sizeable & High & $\begin{array}{l}\text { High, reserving } \\
\text { options }\end{array}$ \\
\hline & \multicolumn{4}{|c|}{ Varies with increase } \\
\hline Increasing further & $\begin{array}{l}\text { Virtually } \\
\text { certain }\end{array}$ & Sizeable & High & $\begin{array}{l}\text { High, reserving } \\
\text { options }\end{array}$ \\
\hline \multirow{2}{*}{$\begin{array}{l}\text { Further reduction leads to low } \\
\text { discharges, greater restrictions }\end{array}$} & Very likely & Small & Moderate & Low \\
\hline & \multicolumn{4}{|l|}{ Likely } \\
\hline $\begin{array}{l}\text { Discharge could present } \\
\text { problems during extremes }\end{array}$ & $\begin{array}{l}\text { Virtually } \\
\text { certain }\end{array}$ & Limited & High & Low \\
\hline
\end{tabular}

4 The added value of policy indicates the extent to which harmful effects can be avoided or mitigated by policy choices, both proactive and reactive. This added value is divided in to the categories 'low', 'moderate' or 'high'.

5 Which proportion of the policy added value is exclusively preventive?

6 There are at least two problems with the monetarisation of the effect here. First, the monetarisation of biodiversity is extremely uncertain. Secondly, in this specific case, the disutility (the negative value) is not the difference between an initial situation and a final situation, but the change itself. 


\subsection{W ATER AS A PHYSICAL PLANNING PROBLEM}

\subsubsection{STANDARDS FOR WATER MANAGEMENT}

The standards for the primary flood defences in the Netherlands originate from the Delta Commission (Deltacommissie, 1960) which, following the flood disaster of 1953 , was given the task of finding ways of protecting the Netherlands against flooding. The Commission formed a view based on a cost-benefit analysis, in which at the optimum protection level the marginal costs of a further increase in flood safety were equal to the marginal benefits. It is striking that the standards established then still serve to this day as a guideline for flood protection. Climate change is gradually increasing the physical flooding risks. However, an even greater threat is posed by growing population density and rising prosperity, which have led to a sharp increase in the value of the assets to be protected. A cost-benefit analysis on this basis would result in more stringent safety standards. In addition, prosperity generally fosters risk avoidance: safety is a luxury commodity. This could be expected to have raised the protection standard further. The reform of the Flood Defences Act (Wet op de waterkering) seeks to take in to account the growing population density in areas protected by dykes and the increasing economic value by stipulating the publication of a report every ten years on the risk and impact of flooding and the consequences for safety standards. The first such report is scheduled to be published in around 2008 .

The Delta Commission set a standard for the protection western coasts of the provinces of Noord-Holland and Zuid-Holland a frequency of occurrence ratio of 1:10,000 times per year; the standard for the flood defences in the coastal provinces of Zeeland in the south and of Friesland and Groningen in the north was 1:4,000 per year. With regard to river flooding, in consultation with the Province of Gelderland the Minister of Transport, Public Works and Water Management established the norm discharge rate from the River Rhine at 18,000 cubic metres per second, with an incidence probability of 1:3,000. This meant that the majority of the dykes had to be greatly reinforced. However, implementation of this project led to so much public unrest that in 1975 the Minister of Transport, Public Works and Water Management ordered the Becht Commission to re-examine the norm. The Commission concluded that a much lower norm of 1:1,250 per year could be safely applied. The Commission calculated that this was equivalent to a norm discharge rate of 16,500 cubic metres per second (Commissie Rivierdijken 1977). After persistent public resistance to the strengthening of river dykes, the Minister of Transport, Public Works and Water Management installed the first Boertien Commission, which recommended lowering the norm discharge rate to 15,000 cubic metres per second. For the River Meuse, a second Boertien Commission recommended a norm discharge rate of 3,650 cubic metres per second, with an incidence probability of 1:1,250 per year (Commissie Watersnood Maas 1994). The initially high safety standards for the major rivers were thus steadily reduced in response 
to public pressure, and the implementation of projects was deferred further and further in to the future. Public support among those living around the rivers proved to be extremely weak, with half the population squarely against dyke reinforcement (Hufen 1998). The floods in 1993 and 1995 increased the sense of urgency only temporarily. Some of the flood defences do not comply with the current norms.

Mean while, the realisation is beginning to dawn that climate change could pose further problems for the Dutch river delta in the more distant future. The Commission on Water in the 21st Century (Commissie Waterbeheer 21e eeuw) has developed water supply scenarios for the Rhine and Meuse rivers. Table 3.2 shows that the norm water discharge rate has been raised further. The margins of uncertainty in this norm discharge rate are considerable, however: translated in to the required dyke height, the margin of uncertainty is approximately one metre.

Table 3.2 Norm water discharge rate in different climate scenarios $(\mathrm{m} 3 / \mathrm{s})$

\begin{tabular}{|c|c|c|c|c|}
\hline & Present & Minimum & Medium & Maximum \\
\hline & & \multicolumn{3}{|l|}{ Projection year: 2050} \\
\hline Temperature & & $+0.5^{\circ} \mathrm{C}$ & $+1^{\circ} \mathrm{C}$ & $+2{ }^{\circ} \mathrm{C}$ \\
\hline Rhine & 16,000 & 16,400 & 16,800 & 17,600 \\
\hline \multirow[t]{2}{*}{ Meuse } & 3,800 & 3,990 & 4,180 & 4,560 \\
\hline & & \multicolumn{3}{|l|}{ Projection year: 2100} \\
\hline Temperature & & $+1^{\circ} \mathrm{C}$ & $+2{ }^{\circ} \mathrm{C}$ & $+4^{\circ} \mathrm{C}$ \\
\hline Rhine & & 16,800 & 17,600 & 18,000 \\
\hline Meuse & & 4,180 & 4,560 & 5,320 \\
\hline
\end{tabular}

Source: Baseline report by the Commission on Water in the 21st Century (WB21 2000b)

A norm water discharge rate of 18,000 cubic metres per second is seen as a maximum for the Rhine, because a higher rate of discharge would flood the dykes in Germany. If Germany were to raise its dykes further, contrary to current international agreements, the norm discharge rate in the Netherlands could be increased further. A changing climate could prompt such a move.

The Dutch National Institute for Public Health and the Environment (RIVM 2004: 80) has highlighted the selective way in which new knowledge is used: knowledge which indicates a reduction in base levels tends to find its way into policy more readily than, say, knowledge which suggests greater uncertainties or a higher base level than first assumed. 


\subsubsection{SUBSTANTIVE SOLUTION OPTIONS}

Given the uncertainty surrounding the likely developments, adaptation to climate change must be aimed at robustness. Urbanisation, agriculture, nature and infrastructure place competing claims on the available space which together exceed the size of the Netherlands. Space is a scarce commodity in the Netherlands which must be handled with care. Choices have to be made between acceptance (of flooding risks in certain localities), space (relocation of functions and/or releasing space for flexible water defence) and technology (pumping stations and flood defences).

\section{The rivers}

There is a growing realisation that the danger of flooding could increase as a result of climate change. In response to this, the focus of attention has broadened, to take in not just vertical water protection (strengthening dykes), but also horizontal water retention in the sense of creating more space for water. The policy memorandum 'Room for the River' (Ruimte voor de rivier 1996) contain s a commitment to reserve and create space for the rivers in the interests of safety and to limit the damage from flooding. However, pressure on the available space is increasing in the Netherlands and the tendency is if anything to provide the rivers with less rather than more space. In this sense, the policy memorandum represents a break with the past.

There are three options for tackling flooding risks (Klijn et al. 2004). The first is the usual strengthening and raising of the river dykes, combined with maintenance of the channel. The second offers room for the rivers in the form of a series of flood plains which are allowed to flood at high water. Existing dyked areas would have to be split up into smaller dyked sections to accommodate this, so the economic damage would be minimised when the flood plains were under water. High standards would have to be set for the dyking of economically valuable areas. A third option is to configure the space set aside for the rivers in such a way that new channels are created which are used only at high water.

The timing of these different solution options varies. The first two options could be carried out in phases, but the opportunities for phasing in the third option are limited. There is great uncertainty regarding the development of the necessary run-off capacity; it could transpire that the first approach based on vertical reinforcement, which is also the cheapest option, is ultimately inadequate. It could also turn out that the third approach, which is the most expensive, was ultimately not necessary.

The Commission on Water in the 21st Century (WB21 2000a) has defined water as a spatial problem with the 'three-stage strategy for water quantity', based on the following priority order: retain - store - discharge. This priority order is based partly on the desire to accommodate water shortages during periods of drought. The Commis- 
sion estimates that in the period to 2015 approximately 40,000 hectares will be needed for the main water system and a further 15,000 hectares for the regional water systems. Between 2015 and 2050 a further 20,000 and 35,000 hectares, respectively, would need to be added.

\section{Land consolidation and land use}

The problems of water management are not limited to the major rivers, and climate change is not the only cause of problems in other areas. In the lower regions of the Netherlands, in particular, subsidence due to soil erosion is a problem, caused by oxidation of the peaty soil in moorland areas on contact with air. The decline in soil levels can amount to as much as a metre per century, and will lead to an increase in the amount of damage in the event of flooding. The erosion also leads to more backing up of water as the major rivers discharge into the sea; the rise in sea levels exacerbates this problem.

The soil erosion process is exacerbated by low groundwater levels. In many places those levels are actively reduced to facilitate building and agricultural activity. However, higher water levels are desirable in moorland pasture areas in order to retain water for longer, combat drought and slow down the process of soil erosion (VROMraad 2002). Creating more space for water would therefore benefit a sustainable water management regime, especially in the regional water systems.

\section{The sea}

There are currently a number of weak links in the Dutch coastline (RIVM 2004). Coastal defences are of course by definition defensive, but this does not mean they have to be inflexible. The sand replenishment policy is effective in maintaining the coastline, but in addition, coastal defence systems further inland are also a realistic option in some localities, as long as the necessary space is set aside for this.

See water levels are just one of the relevant factors in coastal defence; wind, wind direction and wave height are at least as important. The knowledge about waves, in particular, is fairly recent and is increasing gradually. Waves probably impose a considerably heavier burden than the hydraulic parameters allow for. On the other hand, the frequency of storms has reduced in the last fifty years, though of course this offers no guarantees for the coming century.

\section{The costs of water policy}

The Delta Commission regarded spending $0.5 \%$ of GDP on measures to protect against the risk of flooding as 'by no means infeasible'. Current spending is below this by around a factor of 3 . This would seem to be on the (very) low side, because the value of the assets to be protected has increased significantly (expected value = probability times effect) and because increased prosperity also influences the risk preference (the price of risk). Both factors justify establishing a lower accepted flood risk than 
at present. What is particularly striking about estimates of the costs of increasing flood safety (Rooijers et al. 2004; Klijn et al. 2004; WB21 2000a) is that they lie so far below the cost-benefit norm applied by the Delta Commission. The conclusion is that the expected expenditure due to climate change in the next century will remain completely manageable, even if water policy becomes significantly more expensive due to that climate change.

Physical planning policy is largely a matter of choosing from various options. Regulation is needed to ensure that investments are not made in localities which will later be designated as wet landscape areas, since this would make that designation more difficult.

\subsection{W ATER AS AN ADMINISTRATIVE PROBLEM}

There are several administrative aspects relating to the draining of the major rivers in relation to climate change. It became clear in the foregoing section that the necessary measures can have far-reaching physical planning consequences. It is uncertain whether the statutory instruments needed to claim the required space are adequate. Measures which have a radical impact on the physical landscape are conditional on sufficient public support.

\subsubsection{LEGAL I NSTRUMENTS}

Ensuring safety from the danger of flooding from the sea and major rivers is the responsibility of the State, in conjunction with the regional authorities. The main outlines of the policy are established at central government level in the policy memorandum on water management (Nota voor de Waterhuishouding). Plans developed by central government often have consequences for physical planning, creating an interface between water management policy and physical planning policy. At the heart of this interface is the weighing of spatial functions against each other. At government level, however, there is no coordination between water management policy and physical planning policy (Groothuijse and Van Rijswick 2005)., and elements of policy formulated at central government level are sometimes lost in the translation to regional level due to physical planning considerations. Central government formulates the water management policy based on a unilateral social interest. More interests are at stake at regional level, and these have to be weighed against each other. From the point of view of safety, the result of this exercise can be regarded as unsatisfactory.

The government needs greater powers to steer the implementation of major water management projects. The present statutory instruments offer some scope for this (key planning decisions), but fall short of what is needed in practice (Van Buuren and Laninga-Busch 2005). The question is whether setting aside physical planning areas 
should be seen as indicative policy statements or concrete policy decisions. The usefulness of an indicative policy statement depends on the cooperation of local authorities. In a concrete policy decision all relevant interests must be taken in to account, including local interests. This makes large-scale use of this instrument by central government less appropriate, and means that the commitment of provinces and water boards is essential. In reality this mean s that recourse is sought to the usual administrative influence of central government. All in all, the responsible ministers consider these options to be insufficient.

The Advisory Committee on Water Management Legislation (Commissie van Advies inzake de Waterstaatwetgeving) was recently asked to assess the applicability of these statutory instruments for large-scale physical planning exercises in relation to the anticipated discharge from the major rivers. According to the Committee, there is no need to develop new legislation for water management and the new Spatial Planning Act (Wet ruimtelijke ordening, WRO) could in time prove to be effective for the creation of protected zones, buffer zones and areas reserved for wet landscape functions (Van Buuren and Laninga-Busch 2005). The new Act will increase the powers of central government to achieve its own physical planning objectives. One condition is that there should be agreement between the Minister of Transport, Public Works and Water Management and the Minister of Housing, Spatial Planning and the Environment (VROM).

\subsubsection{PUBLIC SUPPORT}

Physical planning decisions that lead to urbanisation are to all intents and purposes irreversible. The high costs of de-urbanisation mean that areas designated for construction ('red' planning areas) will not be easy to change into designated 'green' areas (nature) or, in the case of water management, into 'blue' areas (water). Physical planning thus by definition has long-term consequences. The question now is whether water management can dominate the use of space. Put simply, can 'red' follow 'blue', or must 'blue' follow 'red'? In the past the importance of safe water management has been subordinated to other interests, both physical planning-related and financial. The importance of safe water management was less firmly embedded in the social and administrative bedrock.

The tensions between the various administrative layers became visible in the preparations for the key planning decision Room for the River. At provincial and local level, agricultural interests and housing interests weighed more heavily than at central government level. The 'interactive decision-making' meant that interests contributed by central government were weighed against provincial and local interests. While this is not a mistaken approach in itself, in matters of national importance it is key that this should result in a better 'fit' in the local context rather than a watering down of national objectives. 
Measures to increase flood safety require support. In the case of the large rivers, which fall under central government responsibility, this not only means support among local administrators, but also among the local population. Hufen (1998) argues that lack of public support has been a key factor in faltering administration, which in turn has led to the watering down and delays in the original plans to raise the safety level of the large rivers to a disaster probability of 1:3,000. The public memory of major catastrophes such as the flood disaster of 1953 is relatively short.

In the light of climate change and the intensification of the water cycle it is expected to bring, the ambitions of the key planning decision do not go far enough. This means that there are currently no preparations under way for reserving proposed wet landscape areas for further measures. The consequences of climate change place demands on the administration to curb the risk of major flooding due to extreme discharges from the major rivers. Against this backdrop, the preparation of the key planning decision Room for the River is no more than a first step. By taking a key planning decision, the government establishes its position for the longer term. It will not be simple to prepare another major decision for the same area which in reality addresses the same problem.

\subsubsection{ADMINISTRATIVE COORDINATION AT INTERNATIONAL LEVEL}

The European Water Framework Directive (2000/60/ec) forms the basis for international coordination. It focuses is mainly on environmental objectives in relation to water quality and sustainable water management and pays scant attention to ameliorating the consequences of flooding; that falls within the scope of the (international) River Basin Management Plan. The Water Framework Directive pays no attention to the detailing of quantitative water management. The Directive was drawn up on the basis of the collaborative model developed by the Rhine riparian States, which work together in the International Commission for the Protection of the Rhine (ICPR). The ICPR plays a part in the formulation of the River Basin Management Plan for the Rhine, and devotes wide attention to flooding risks.

Retaining water in the upper basin area is of little importance in practice for extreme discharges, because in those situations the soil is generally already saturated. Some gain s could however be made in the longer term from changed land use. Measures have been taken on a large scale to lower water levels and promote discharge. These increase the local discharge capacity and therefore raise the risk of flooding downstream. To some extent these measures could be implemented with less downstream impact. 
If climate change increases the discharge of water from the Rhine, new ways will have to be found of distributing the flooding between Germany and the Netherlands. Both countries, but in particular Germany, can benefit from this. In Germany there is in principle scope for extra buffering of Rhine water, but measures to combat flooding are also possible in the Netherlands. Preferably, measures should be taken where they are cheapest. 
CLIMATE STRATEGY - BETWEEN AMBITION AND REALISM 


\section{EMISSI ON REDUCTION AS A TECHNICAL STRATEGI C I SSUE}

\subsection{NTRODUCTION}

It makes no difference for the climate whereabouts in the world greenhouse gases (GHGS) are emitted or absorbed. Since emission reduction measures can be taken anywhere, their potential and cost-effectiveness is not determined by the specific national situation, but by the global situation. From a technical point of view, therefore, emission reduction as a solution to the climate problem is a global challenge. This chapter therefore looks at emission reduction as a technical strategic issue from a global perspective.

The magnitude of the emission reduction challenge is dictated by the contributions of the various greenhouse gases, their sinks and the anticipated increase or decrease in emissions over time. The following questions are central here:

- What are the main sources of emission and absorption in terms of their magnitude and dynamics, by sectors and by countries/continents?

- How far would emissions have to be curbed in order to achieve the European Union's (EU) $2^{\circ} \mathrm{C}$ target?

- Within what timeframe would emission levels have to be reduced?

If we focus on emission reduction policy, in what directions do we need to look for solutions:

- What are the main technical options as regards reduction potential and maturity? The more pressing the time, the greater the need for available technologies which can be fitted into existing systems and practices.

- How cost-effective are the various options? The importance of cost-effectiveness increases as the need to engender support for climate policy spreads to developing countries.

- What is their synergy with other options, so that options can benefit from each other, and what synergy do they show with other social objectives such as security of energy supplies and economic development?

- Does today's knowledge offer a reasonable perspective of timely emission reductions in the first half of this century?

This chapter is structured as follows. Section 4.2 translates the EU's $2^{\circ} \mathrm{C}$ target into an emission reduction programme for $\mathrm{CO}_{2}$ and other greenhouse gases (OGGS) for the next fifty years and shows the gulf compared with a BAU (Business As Usual) situation. This first exploration produces four emission reduction routes: three for $\mathrm{CO}_{2}$ and one for OGGS. The potential contribution of these routes is then examined in sections 
4.3 to 4.6 inclusive. Section 4.7 derives a global climate strategy from the reasoning followed, based on the criteria of cost-effectiveness, the importance of involving developing countries and the timing up to around 2050 from the perspective of risk reduction. The Council believes that this strategy should also shape the efforts of the Netherlands and the EU.

\subsection{THE EMISSION REDUCTION CHALLENGE FOR FOSSIL $\mathrm{CO}_{2}$}

\subsubsection{THE PERIOD UP TO 2030-2050 IS CRUCIAL FOR THE $2^{\circ} \mathrm{C}$ TARGET}

The EU has opted for the $2^{\circ} \mathrm{C}$ target, i.e. limiting the rise in average global temperatures to no more than $2{ }^{\circ} \mathrm{C}$ compared with the pre-industrial situation. Based on current knowledge (IPCC 2001 ; Goldemberg 2000), indications are that the concentration of carbon in the atmosphere must not be more of than around $550 \mathrm{ppmv} \mathrm{CO}_{2}$ equivalents in the year 2100, made up of 450-470 $\mathrm{ppmv} \mathrm{CO}_{2}$ and 80-100 ppmv $\mathrm{CO}_{2}$ equivalent OGGS. As GHGS remain in the atmosphere for a long time, it can to some extent be said that there is a $\mathrm{CO}_{2}$ budget for the coming century. Keeping the maximum concentration to $450 \mathrm{ppmv} \mathrm{CO}_{2}$ will require a rate of emissions from year to year that will prove far from simple to achieve, even technically, leaving aside the required international coordination (see chapter 5). Although in this emission reduction programme global emissions can be as much as $20 \%$ above 1990 levels in 2025, they must reach their peak around that time. Thereafter, according to Elzen and Meinshausen (2005), they will have to fall quickly enough to en sure that by $2050 \mathrm{CO}_{2}$ emissions have reduced by around 30-35\% compared with 1990 (depending partly on the reduction of OGGS). After 2050 emissions would need to fall further until emission and absorption rates were equalised in 2100 . The first half of this century is therefore a crucial period for emission reductions.

\subsubsection{THE GULF COMPARED WITH 'BUSINESS AS USUAL'}

Using the 'Kaya Identity' enables the rate of growth in energy-related $\mathrm{CO}_{2}$ emissions to be analysed into a number of constituent variables, namely the growth in the population, per capita gross domestic product (GDP), the energy per unit GDP and the $\mathrm{CO}_{2}$ emissions per unit energy, respectively. Among these factors, only energy consumption and the carbon intensity of the energy are open to influence. For a Business As Usual (BAU) scenario, the forecast by the International Energy Agency (IEA 2004) suggests that global gdp will grow by around $3 \%$ per year. Even if the energy intensity in BAU scenarios falls by $1.5 \%$ per year (estimates in the literature range between $1.2-1.5 \%$ per year), this means that energy consumption in the period up to 2050 will grow by $1.5 \%$ per year (Pacala and Socolow 2004a). The IEA expects little change in the carbon 
intensity of the energy mix. This means that in a $\mathrm{BAU}$ scenario $\mathrm{CO}_{2}$ emissions will rise by around $1.5 \%$ per year up to 2050 . The cumulative emissions in 2050 will be $100 \%$ higher than today, whereas the $2{ }^{\circ} \mathrm{C}$ target set by the EU requires an emission pathway which, after initially rising, ends up around $30 \%$ lower than today in 2050. Translated into an emissions budget, this implies a cumulative emission reduction challenge of approximately $175 \mathrm{GtC}$ in the period up to 2050 (Pacala and Socolow 2004a; 2004b; Hawkins and Williams 2005; Stokes et al. 2004; IPCC 2001).

\subsection{ROUTE 1: GREATER ENERGY EFFI CI ENCY}

Without improvements in energy efficiency, population growth and rising prosperity will inevitably lead to a virtually proportionate growth in energy consumption, which with the present energy system will mean a virtually proportionate increase in emissions. BAU scenarios always assume a gradual spontaneous improvement in energy efficiency, both in end consumption and in the conversion of primary energy to energy for end consumption.

Efficiency improvements are to a large extent achieved through the gradual penetration of new, more efficient equipment and capital goods. In the transport sector, an improvement by a factor of 3 appears technically achievable. There are still a great many gains to be made with buildings, too. Estimates suggest that a combination of improved efficiency in end use and in electricity generation could open the way to a reduction in energy intensity by $2 \%$ per year. It would therefore seem that energy efficiency can make a very major contribution to achieving the required $\mathrm{CO}_{2}$ reduction in the period up to 2050 compared with the BAU scenario. The potential reduction is 3.4 GtC per year in 2050 .

Energy efficiency is sensitive to policy. The degree to which technical possibilities are achieved also depends greatly on prices, which can also be influenced through policy. In the Dutch situation, too, the technical potential for efficiency improvements is of the order of $2 \%$ per annum, but with the currently proposed policy it is likely that less than $1.5 \%$ per annum will be achieved (Daniëls and Farla 2006: 50).

In order to maximise the contribution of improved energy intensity to resolving the climate problem, we take as a basis the optimistic hypothesis that a global improvement of $2.3 \%$ per annum can be achieved ( $2 \%$ in efficiency improvements $+0.3 \%$ structural effect). A powerful and successful drive towards energy efficiency could enable this to be realised, though it would be an unprecedented success if such a tempo were to be achieved quickly at global level and then sustained for successive decades.

The assumed optimistic improvement in energy inten sity reduces the upward effect on emissions growth of GDP growth from $3 \%$ per year to $0.7 \%$ per year, averaged over 
the period 2000-2030. As long as the energy mix does not change, emissions will grow even in this optimistic scenario by more than $40 \%$ up to 2050 , however, whereas to achieve the $2^{\circ} \mathrm{C}$ target a reduction of $30 \%$ is desirable. Improving energy efficiency alone will therefore not be enough to achieve the eu's climate objective. If the aim was to bridge this gulf through a change in the energy mix, the proportion of fossil fuels in the growing energy consumption would not be able to increase from $80 \%$ to $82 \%$ as in a BAU scenario (IEA 2004), but would have to fall to around $40 \%$.

\subsection{ROUte 2: ALteRING THE GLOBAL ENERGy MIX}

Even with a far-reaching improvement in energy efficiency, economic growth will be accompanied by rising $\mathrm{CO}_{2}$ emissions. This makes the development of low-emission energy an urgent requirement. Section 4.4.1 discusses the key conditions for achieving emission reductions via the energy mix. Section 4.4.2 looks at how the energy mix could be addressed. Finally, section 4.4 .3 explores ways of bringing about the required innovation.

\subsubsection{KEY CONDITIONS: COAL, ELECTRI CITY, DEVELOPING COUNTRIES}

\section{Coal is the crucial fossil fuel}

The main fossil fuels are gas, oil and coal. Finding an alternative to gas has the lowest priority, as gas has the lowest $\mathrm{CO}_{2}$ emissions per unit energy, while coal has the highest. There is therefore if anything an argument for extending the use of gas in the coming decades, especially at the expense of coal. The main application for this increase would be in the generation of electricity. The IEA is predicting an increase in the share of gas in electricity generation from $36 \%$ to $47 \%$ by 2030 .

Looking for alternatives for oil is more relevant, both from the perspective of climate policy and with a view to securing energy supplies. A relevant aspect for the climate is that oil is currently responsible for $41 \%$ of $\mathrm{CO}_{2}$ emissions; according to the $\mathrm{BAU}$ growth path, this falls slightly to $39 \%$. Security of energy supplies is at least as urgent as the climate (especially in a BAU development), because the peak for conventional oil is coming into view and the transport sector is dependent almost entirely on oil. Another threat to the security of energy supplies is the heavy dependency on just a few regions, in particular the Middle East and Russia. In the words of EU Commissioner Piebalgs: "By 2030 Europe will be dependent on imports for $90 \%$ of its oil consumption and $80 \%$ of its gas consumption; these trends are unbroken, despite Europe's commitment to developing renewable energy."

Coal is the most relevant fuel from a climatic point of view. Coal use is growing by $1.4 \%$ annually. Almost $70 \%$ of coal used is burned in the generation of electricity, the 
fastest-growing of all sectors, and this is projected to grow to $79 \%$ by 2030 . This will take the share of coal in global generating capacity to almost $40 \%$. In a BAU scenario, the share of coal in the primary energy chain remains virtually unchanged (23\% today, $22 \%$ in 2030), partly because the capital stock of power stations is geared to coal. Coal is relevant particularly because of its high carbon intensity and wide availability. Consumption of the existing stocks of oil and gas fits within the $\mathrm{CO}_{2}$ budget for the coming decades, while the use of coal does not. For many countries, coal is the primary option for energy supply security (McFarland et al. 2004; ciab/IEA 2005). Moreover, coal is becoming more important because in the near future it will be possible to use gasification technology to make both clean gas and liquid fuel for transport from coal. This means that if the oil price should end up at a permanently high price, and if conventional oil stocks should peak between 2015 and 2035, the role of coal could become even more important.

\section{Electricity: the crucial sector}

Electricity and transport are far and away the most relevant sectors when it comes to addressing $\mathrm{CO}_{2}$ emissions via the energy mix because they take the largest share of total energy consumption and are the strongest growing sectors (see table 4.1). In a BAU scenario, it is anticipated that in 2050 no less than three-quarters of $\mathrm{CO}_{2}$ emissions will come from these two sectors: half from electricity generation and a quarter from transport.

Table 4.1 Distribution of fossil $\mathrm{CO}_{2}$ emissions (in \%)

\begin{tabular}{lrrrrrr}
\hline & \multicolumn{2}{c}{ World } & \multicolumn{2}{c}{ Developing } & \multicolumn{2}{c}{ OECD } \\
& \multicolumn{3}{c}{ countries } \\
& 2002 & 2030 & 2002 & 2030 & 2002 & 2030 \\
\hline Electricity & 39.8 & 43.9 & 40.7 & 48.7 & 38.5 & 39.1 \\
Transport & 20.8 & 22.8 & 15.1 & 18.2 & 27.2 & 30.7 \\
Industry & 17.4 & 14.6 & 23.7 & 16.3 & 13.8 & 12.3 \\
Built-up environment + services & 13.6 & 11.5 & 13.0 & 10.5 & 14.5 & 12.3 \\
Other & 8.0 & 7.0 & 7.3 & 6.2 & 6.0 & 5.6 \\
Total & 100 & 100 & 100 & 100 & 100 & 100 \\
\hline
\end{tabular}

Source: IEA 2004: 75

Reducing emissions in the electricity sector is important in the short term. There are four reasons why electricity is a key sector. First, the sector is large and consumption is growing strongly, especially in developing countries, and a great deal of energy is lost in the conversion process. Second, table 4.2 shows that coal takes the largest share in the supply of energy for electricity generation, at $39 \%$. Thirdly, the scale of electricity generation offers great benefits of scale in making the process carbon-neutral. And finally, many old power station - especially in the OECD countries - are in urgent 
need of replacement, while the total number of power stations is set to be increased significantly in the near future to meet the growing demand for electricity. Given the long life of power stations, there is therefore a closing window of opportunity.

The transport sector can currently make a limited contribution to mitigating emissions by addressing the fuel mix. The mitigating effect of first-generation biofuels (bio-ethanol, biodiesel) is limited because their production generates relatively large amounts of $\mathrm{CO}_{2}$. Large-scale use of hydrogen is unlikely before 2050 for a number of reasons. Substitution of fossil fuels in the transport sector is therefore an issue for the longer term. The remaining stocks of conventional oil will therefore undoubtedly be used mainly for transport.

Table 4.2 Electricity: shares by fuels and region (in \%)

\begin{tabular}{lrrrrrrrr}
\hline & \multicolumn{2}{c}{ World } & \multicolumn{2}{c}{ OECD } & \multicolumn{2}{c}{$\begin{array}{c}\text { Transitional } \\
\text { countries }\end{array}$} & \multicolumn{2}{c}{$\begin{array}{c}\text { Developing } \\
\text { countries }\end{array}$} \\
& $\mathbf{2 0 0 2}$ & $\mathbf{2 0 3 0}$ & $\mathbf{2 0 0 2}$ & $\mathbf{2 0 3 0}$ & $\mathbf{2 0 0 2}$ & $\mathbf{2 0 3 0}$ & $\mathbf{2 0 0 2}$ & $\mathbf{2 0 3 0}$ \\
\hline Fossil fuels & & & 62 & 64 & 63 & 72 & 74 & 78 \\
$\cdot$ Coal & 39 & 38 & 38 & 33 & 22 & 16 & 45 & 47 \\
$\cdot$ Oil & 7 & 4 & 6 & 2 & 4 & 2 & 12 & 5 \\
- Gas & 19 & 30 & 18 & 29 & 37 & 54 & 17 & 26 \\
Nuclear energy & 17 & 9 & 23 & 15 & 18 & 11 & 2 & 3 \\
Hydropower & 16 & 13 & 13 & 11 & 19 & 15 & 23 & 16 \\
Other renewable fuels & 2 & 6 & 3 & 10 & 0 & 2 & 1 & 3 \\
\hline
\end{tabular}

Source: IEA 2004: 197

\section{Developing countries: the crucial region}

Table 4.3 shows that the anticipated growth in energy consumption will take place primarily in developing countries. A significant and growing proportion of the emission reduction measures will therefore have to be taken outside the OECD, and especially in Third World countries.

Table 4.3 Share of regions in $\mathrm{CO}_{2}$ emissions according to the BAU scenario

\begin{tabular}{lccc}
\hline Share in global $\mathbf{C O}_{2}$ emissions from fossil fuels Grow th in emissions \\
& 2002 & 2030 & $2002-2030$ \\
\hline OECD & $52.8 \%$ & $42 \%$ & $27 \%$ \\
Transitional countries & $10.3 \%$ & $9 \%$ & $43 \%$ \\
Developing countries & $34,9 \%$ & $49 \% \mathrm{a}$ & $123 \%$ \\
Total & $23 \mathrm{GtC}$ & $35 \mathrm{GtC}$ & $62 \%$ \\
\hline
\end{tabular}

a According to the weto-ref scenario: $41 \%$ in 2030 (European Union 2003). Cumulative emissions in 2000: 47\%, and in 2030 more than in the developed countries (MITI).

Source: IEA 2004: 75 


\subsubsection{RESULTS VIA THE ENERGY MIX}

The foregoing made clear that coal, electricity and developing countries are crucial factors in achieving emission reductions via the energy mix. It also established that achieving emission reductions via the energy sector (improved efficiency and different energy mix) will require a reduction in the global share taken by fossil fuels in the growing energy consumption, from $80 \%$ now to around $40 \%$ in 2050 . It immediately follows from this that the share of carbon-neutral energy in total energy consumption would then have to increase from its present $20 \%$ to $60 \%$ by 2050 , instead of falling as anticipated in BAU scenarios. This increase would have to be achieved against the backdrop of rapidly growing electricity consumption. The question is how this could be done:, i.e. via which combination of modern renewable energy, nuclear energy and clean fossil energy.

\section{In BAU scenario no growth in share of carbon-neutral energy}

According to the BAU models developed by the IEA, it is the growth in consumption which brings about the fall in the proportion of carbon-neutral energy. The present $20 \%$ of carbon-neutral energy can be broken down into $6.7 \%$ nuclear energy and $13.5 \%$ renewables. Although the IEA expects the production of nuclear energy to grow in terms of $\mathrm{kWh}$, no growth is foreseen in market share. Instead, that share will fall from $6.7 \%$ to $4.6 \%$ in 2030 as several countries do not replace nuclear power stations that have reached the end of their life. The IEA also expects the share of renewable energy to remain at $13.5 \%$ in the coming decades. This stabilisation is the net result of the following shifts:

- The share of traditional biomass will fall from $7.3 \%$ to $5.6 \%$ in 2030 .

- The share of modern biomass will grow from $3.4 \%$ to $4.1 \%$ in 2030.

- Solar and wind power will together triple from $0.5 \%$ to $1.6 \%$.

- Hydropower will stabilise at $2.2 \%$. The volume growth will be just enough to keep pace with the growth in energy consumption.

Together, the new renewables (modern biomass, solar and wind power) will grow thanks to government support from a share of $4 \%$ in 2002 to a share of just $5.7 \%$ in 2030 , despite a doubling in volume. If the IEA forecast in a BAU development is taken as a basis, then there are only two serious options for an emission reduction route involving a carbon-neutral energy mix: nuclear energy or modern renewable energy.

\section{Betting on modern renewable energy?}

If the share of nuclear energy does not increase, but stabilises at 6\% (the production in terms of $\mathrm{kWh}$ will then still grow), the share of modern renewable energy would have to increase from $4 \%$ in 2002 to around $46 \%$ in 2030 . Clearly such a major leap forwards is virtually impossible, but it is nonetheless discussed below. 
In order to realise the required share of modern renewable energy, fossil energy would have to be eliminated almost entirely from the electricity sector, and this would moreover have to take place within the next few decades. This is because electricity generation accounts for around 35\% of primary energy, and shifts within the electricity sector therefore impact on a third of the total energy mix. The electricity generation sector just happens to be on the verge of a major new wave of capital investment. Since all these new power stations will have a life cycle that takes them well into this century, virtually all new capacity ought to be based on modern renewable energy. All power stations which are currently expected to be fuelled by coal, oil or gas would then have to be fuelled by wind energy, solar energy and/or modern biomass. Solar energy is not yet mature enough for broad application in the electricity generation sector. Wind energy currently costs between 1.5 and three times as much as energy generated in conventional power stations. The $\mathrm{CO}_{2}$ price of wind energy is between EUR 95 and EUR 240 per tonne of avoided $\mathrm{CO}_{2}$, depending among other things on what proportion of the costs of the conventional reserve capacity that must be maintained to accommodate unpredictability in the supply of wind energy is attributed to wind energy. This also means that a maximum of around $20 \%$ of the electricity can be generated using wind power. Secondgeneration biomass offers potential, but the existing infrastructure (the same also applies for solar and wind power) is insufficiently geared to new forms of sustainable energy. If the low cost-effectiveness is not enough to make this prohibitive in Europe, then this will certainly be the case on the global scale that is required.

\section{Can renewable energy be combined with nuclear energy?}

Is it feasible to achieve the target for the energy mix through a combination of modern renewable energy and nuclear power? As a theoretical exercise, it could be assumed that the share of modern renewable energy in global energy consumption will grow spectacularly in the coming decades to reach $20 \%$ in 2050 and that this growth will take place entirely at the expense of the share taken by fossil energy. Together with hydropower $(2.2 \%)$ and traditional biomass (5.6\%) this would result in a share of $28 \%$ for carbon-neutral energy excluding nuclear energy. In order to make the leap to the required $60 \%$ of carbon-neutral energy, the share taken by nuclear energy would thus have to grow from its present $6.7 \%$ to approximately $37 \%$ of a rapidly growing total, rather than falling to $4.6 \%$. This is not an achievable figure. The authoritative mit study (2003) assumes in what it regards as an ambitious scenario for nuclear energy up to 2050 that there will be a tripling of the installed generation capacity to around $1,000 \mathrm{gw}$. This would take the share of nuclear energy to around $10 \%$ of the primary energy in 2050, equivalent to an additional emission reduction of around $0.8 \mathrm{GtC}$ compared with the present global energy mix.

\section{A contribution from clean fossil energy}

The use of fossil energy would not need to fall so much if it produced less $\mathrm{CO}_{2}$. The two main options for clean fossil energy are: 
- Replacing coal with gas or other fuel

If half the new coal-fired power station s forecast by the IEA with a capacity of 1400 gw were gas-fired, this would lead to a reduction of $0.5 \mathrm{GtC}$ in 2054 . This option has its limitations, however: gas reserves are finite, imported gas is generally more expensive than domestically extracted coal and the dependence on imports is politically unattractive.

- Carbon capture and storage (CCS)

The $\mathrm{CO}_{2}$ that is released unavoidably through the use of fossil energy is stored underground so that it no longer contributes to the greenhouse gas effect. CCS could enable an emission reduction to be achieved of approximately $1.2 \mathrm{GtC}$ per year in 2030 and more than 2 GtC per year in 2050 .

Of these two options - which are in fact not mutually exclusive - CCS offers the greatest potential. The main reason for this is that CCS can be combined with gasification technology (see below) and, in that combination, can render the inevitable large-scale use of coal $\mathrm{CO}_{2}$-neutral. Use of CCS in combination with coal requires additional facilities and costs more, but is nonetheless relatively cheap compared with many other emission reduction options. All parameters of the foregoing subsections are then met: coal, electricity and (in combination with the Clean Development Mechanism (CDM) - see next chapter) developing countries.

Gasification technology is attractive for several reasons: it offers a new and efficient technology for the production of electricity, opens the way to the manufacture of new transport fuels (FT-diesel or dimethyl ether, DME) and hydrogen (later this century), and allows large-scale use of all kinds of biomass (including wood-based) for the generation of electricity and biofuels. Since CCS is an 'end-of-pipe' solution, it is compatible with the existing energy system. In combination with biomass, CCS can actually lead to the net removal of $\mathrm{CO}_{2}$ from the atmosphere. In combination with Enhanced Oil Recovery (Senior et al. 2004; Gielen and Podansky 2004; CIAB/IEA 2005), the oil extraction yield can be increased.

\subsubsection{SEPARATING EMISSION REDUCTION AND ENERGY TRANSITION}

In the period up to 2040-2050 which is so crucial for climate policy, the dominance of fossil energy will be impossible to break; there is too little time to bring about a sufficient improvement in the position of modern renewable energy. Present policy is open to the risk that too much effort will be devoted to efficiency and modern renewable energy, with the result that far too few results will have been achieved by 2050 . This is all the more relevant because both routes are especially relevant for electricity generation and are therefore potentially each other's competitors. High efficiencies for fossil-fuelled power stations are not good for the competitiveness of modern renewa- 
ble energy, and the replacement of gas by renewable energy is given little priority in any event. The anticipated high share of (cleaner) fossil-fuel power stations when new investments are made will greatly slow down the transition to carbon-neutral energy.

If the achievement of the $450 \mathrm{ppmv}$ target is not to be made impossible in advance, it would be better to separate the goals of timely emission reduction and transition to a new energy system. Securing a substantial contribution by modern renewable energy to the envisaged emission reduction will demand large-scale use of this energy, and the costs of this young technology could quickly get out of hand. The technology is insufficiently mature to permit its widescale use at this time. A wiser course might be to distinguish between emission reduction programmes based on proven and costeffective technologies on the one hand and R\&D programmes aimed at developing cost-effective technologies in the future on the other. Governments and businesses must gear their R\&D programmes to the possibilities and to reducing costs in niche markets. In the us - unlike the EU - this distinction is already being made.

The transition to a carbon-neutral energy supply will require more patience. There is a need for an R\&D strategy which promises to create the conditions for that transition in a later phase. Niche applications form part of this strategy.

\subsection{ROUTE 3: DEFORESTATION, AFFORESTATION AND LAND-BASED CARBON STORAGE}

The slow but steady fall in the rate of deforestation may be expected continue in a BAU scenario. Experience has shown that when per capita incomes are rising, a moment comes in every country when people cease felling trees to make way for low-output agriculture. The growing demand for food to feed the rising world population is not a real barrier to reduced deforestation and more afforestation; the necessary increase in agricultural output can be achieved without using extra land, provided a steady global rise in yield per hectare of approximately $1.6-1.8 \%$ per year can be achieved. In virtually all IPCC scenarios it is accordingly assumed that the global forested area will increase again in 2100 , offering opportunities for bio-energy. If the falling trend were to continue in a BAU scenario, the annual loss of forested areas in 2050 would be half what it is now (Pacala and Socolow 2004a). The related emissions would then fall from their present $1.1 \mathrm{GtC}$ per year to $0.5 \mathrm{GtC}$ per year.

There are four ways of achieving emission reduction through natural carbon storage: less deforestation ( $0.5 \mathrm{GtC}$ per year lower in 2050 than in a BAU scenario), reforestation (1-1.5 GtC per year), promotion of timber as a construction material and changes in arable farming (0.5-1 GtC per year. This would make a total of 2-3 GtC per year achievable by 2050 . 
Reducing the rate of deforestation can succeed only if it goes hand-in-hand with local and regional development, and can in turn reinforce that development through sustainable forms of timber felling, preferably via plantations. In addition, timber could replace other carbon-intensive intensive raw materials as a construction material and biofuel, leading to synergy effects. It is however a finite route, because the net carbon uptake of fully grown trees is nil and the available area for planting is limited.

\subsection{ROUTE 4: REDUCING EMISSI ONS OF OGGS: THE EXAMPLE OF METHANE}

Methane is the most important of the other greenhouse gases (OGGS), accounting for $65 \%$ (1.8 GtC-equivalents). Laughing gas $\left(\mathrm{N}_{2} \mathrm{O}\right)$ comes a good second with $32 \%(0.9$ GtC-equivalents). Methane is particularly important because it has a marked warming effect and a short period of residence in the atmosphere. Measures targeting methane take effect relatively quickly, opening the way for risk reduction. Methane reduction is also important because, as with forestry, it allows developing countries to be involved in global climate policy (Reilly et al. 2004). Provided it is produced in a controlled way, methane can be used as a source of energy in local communities, both for heating and electricity. Finally, methane is important because, unlike fossil energy, there was no incentive in the past to use methane carefully. As a result there are a great many easy gains to be made at low cost or even with economic returns.

Anthropogenic methane emissions are largely caused by leaking pipelines (half the total emissions come from the former USSR), rotting waste, etc. Methane emissions could be cut by $20-40 \%$ at many sources at relatively low cost, primarily through the transfer of best practice technology and expertise, especially in relation to landfill and the processing of sewage sludge. Emissions from energy production and transport (gas, oil, coal) could be reduced by $80 \%$ using existing technology, and at least half this reduction could be brought about using measures which would be of financial benefit to industry. There are also positive side-effects in the form of improved safety due to reduced explosion hazard (mining), modernisation of production systems and energy yields from captured methane. 50-70\% of the methane released in the coal industry could be captured. Combating deforestation (see section 4.5) would also counter the emission of methane caused by incomplete incineration of biomass (incineration of agricultural waste and wood for heating, cooking and charcoal production). All in all, it can be estimated that methane emissions could be cut cost-effectively to $35-45 \%$ of their present levels in the period to 2050 , equivalent to a reduction of $1 \mathrm{GtC}$ per year in 2050 (see also Kets and Verweij 2005).

Industrial OGGS (especially $\mathrm{N}_{2} \mathrm{O}$ ) lend them selves well to a global agreement, because the problem is relatively manageable: far fewer countries are involved than with $\mathrm{CO}_{2}$, because there are virtually no emissions of industrial OGGS in developing countries 
(Reilly et al. 2004). The Montreal Protocol (see chapter 5) can serve as an example of effective policy here.

\subsection{EMISSION REDUCTION STRATEGY UP TO 2050}

In order to meet the EU's $2^{\circ} \mathrm{C}$ target, global $\mathrm{CO}_{2}$ emissions in 2050 would have to amount to only around $4 \mathrm{GtC}$ per year. This would require a reduction of $10-11 \mathrm{GtC}$ per year compared with a BAU scenario. Table 4.4 shows that an effective emission reduction policy for the coming decades would have to be based on a combination of energy efficiency, CCS (in combination with coal and gas), bio-energy (eventually in combination with CCS), storage of $\mathrm{CO}_{2}$ in forests and soil through photosynthesis, a reduction in the emission of OGGS (especially methane) and finally a residual group comprising mainly wind and nuclear power, but also solar power, geothermal energy and tidal energy. The quantities shown in the table will not be achieved spontaneously, but will require intensive policy. Although there is some reserve (around 10\%) compared with the target up to the year 2050, it cannot be concluded from this that some options can be deleted in advance. Each of the routes has its own obstacles which stand in the way of full realisation of its potential.

Table 4.4 Em ission reduction potential in 2050 (in GtC per year compared with BAU scenario)

\begin{tabular}{lcl}
\hline & Potential & Route \\
\hline Intensification of energy efficiency policy & 3.4 & Efficiency \\
CCS & 2.1 & Energy mix \\
Bio-energy & 1.9 & Energy mix \\
Extra storage via photosynthesis & 2.0 & Forestry \\
Reduction of methane & 1.0 & OGG \\
Miscellaneous & 1.8 & Energy mix \\
Total & 12.2 & \\
\hline
\end{tabular}

Source: WRR

Given the global nature of the climate problem, Dutch and European climate policy must be based on global priorities. Solving the problem must be the central concern, not cleaning our own backyard. Cheap emission reduction options are available in developing economies, and (a great deal) more can therefore be achieved for every euro invested in those countries than here. Technology diffusion is important in the short term, while in the long term the development of new technology is key.

The rule of thumb applied in the Netherlands in the recent period, namely a 50-50 distribution of measures taken domestically and measures in other countries, leads to unnecessary expensive measures which deliver little emission reduction per euro spent and result in an approach which, from a global perspective, is the second choice 
without the envisaged innovation objectives being adequately achieved. The Council recommends that a structural distinction be made between the implementation of emission reduction measures and the transition to a new energy system. Implementation must take place now, using the available technology in those locations where this can be done cheaply. In particular, energy efficiency and the use of CCS in the burgeoning electricity sector in emerging economies are urgent. The transition to carbon-neutral energy requires more patience. 
CLIMATE STRATEGY - BETWEEN AMBITION AND REALISM 


\section{I NTERNATI ONAL COORDI NATI ON OF CLI MATE POLI CY}

\subsection{NTRODUCTION}

The climate is an indivisible public good at world level. The current leaders of the international coordination of mitigation - Japan and the European Union (EU) - are already unable to exert a decisive influence on annual net global emissions, regardless of their willingness to do so and regardless of the costs of doing so. In the longer term (up to 2050) these two leaders will have a steadily declining direct influence. The same applies for the member states of the Organisation for Economic Cooperation and Development (OECD) as a whole. Effective climate policy can thus only succeed if it a global policy. European and Dutch climate policy only make sense if they are embedded in a global approach.

This chapter first describes the global coordination problem in more detail and explores the conditions for effective coordination (section 5.2). Section 5.3 looks more closely at the starting points of global negotiations: structural and short-term interests and existing climate policy. Section 5.4 focuses on the institutional and substantive aspects of global coordination.

\subsection{A CLOSER LOOK AT THE GLOBAL COORDINATION PROBLEM}

\subsubsection{DEFINITION AND CHARACTERISATION OF COORDINATION}

In chapter 1 the coordination problem was divided into three components: the development path of countries that are currently still poor, the distribution of costs and the allocation of efforts. The coordination problem is first and foremost concerned with mitigation, since this is where the need to eradicate 'free rider' behaviour is most urgent. Adaptation problems will mainly be solved regionally and only require international coordination where they go beyond the capacity of a single country or region. The development path of growth countries takes priority in climate issues. Roughly three-quarters of the world population live in developing countries, half of them in countries with a relatively low per capita income. The primary ambition of these countries is to grow.

The development problem demands solutions to the following global coordination issues:

a. Which strategies and options can be developed to bring about a more rapid fall in energy intensity and carbon intensity in developing countries, without undermining their economic growth? 
b. How can developing countries be encouraged to pursue climate policy in those cases where the local ancillary benefits (co-benefits) of climate measures are interesting?

c. Is graduation, the (gradual, multistage) transition from 'developing country' to 'developed country', a workable concept in international organisations, with the obligations and costs that it obviously entails?

d. With or without an answer to question c: how can the present exemptions for (all) developing countries in the Kyoto Protocol be incorporated in agreements in the future in connection with the actual emission pathways or, even better, be defined as justifiable exceptions, which can therefore be of limited duration?

e. How and to what extent can the costs of all these initiatives be reduced or shared through support from the OECD or otherwise (other organisations or institutions such as opec or the World Trade Organization (WTO), bilaterally or multilaterally)?

The distribution and allocation problem is no less tricky. Effective allocation via market instruments requires an initial distribution of the emission scope (and thus the emission rights). There are good political and economic reasons for allocating a disproportionately high initial distribution to developing countries, but there is no straightforward correspondence between such a distribution and the distribution of interests and negotiating positions.

The allocation of mitigation must cost of the world as little as possible. Who pays for it is a different matter. Chapter 4 showed that rational allocation will lead to a great deal of mitigation in poor countries. The most cost-effective means of allocation demands maximum integration of emission reduction within the market mechanism. Where this is not feasible, or not for all participants in the United Nations Framework Convention on Climate Change (UNFCCC), supplementary allocation methods and instruments can be used.

Technology development is an exception. There is both a push-effect (making money available for research) and a pull-effect (relative price changes give the market an incentive to carry out research) at work here. The push-mechanism risks both arbitrary competition with other government expenditure and erroneous selection of technologies. The risk of the pull-mechanism is mainly that it will above all foster the optimisation of existing technologies, which will therefore not lead to great leaps forward.

The distribution issue is closely connected to the distribution of wealth throughout the world, but other factors are also relevant. The negotiation problem consists broadly of three elements, namely the distribution basis, the timing and instrumental flexibility:

- The distribution basis requires a set of interrelated indicators. The (convergence of the) net emissions per head of the population is an example of such an indicator. 
- The timing of mitigation obligations is determined by the sequence in which mitigation options are deployed and by the extent to which countries gradually take on heavier commitments as their development progresses.

- Instrumental flexibility gives countries maximum scope to achieve national and global cost-effectiveness.

\subsubsection{COMPLICATING FACTORS}

There are three factors that complicate global coordination of climate policy:

- There is great uncertainty regarding both the climate problem itself and regarding the costs of emission reduction policy and the outcome of the learning processes needed to develop the necessary innovation. This makes it difficult for participating countries to make an accurate assessment of their interests and makes it unattractive for them to commit to far-reaching objectives, timeframes and strategy (McKibbin 2005).

- A strong incentive to free rider'behaviour hampers coordination, because climate is a global public good. Even non-cooperative players stand to benefit from cooperation, however, for example in the form of no-regret options which cost little or nothing but which do reduce the collective problem of 'free riders'. Cooperative behaviour will not always be based on the interests of stakeholders in being cooperative. The widely used adage 'the polluter pays' is based in the first place on economic motives (i.e. the incentive to pollute less). The fact that this adage also contains a moral element bolsters the negotiating result, but does not form the basis for it. In negotiations without an authoritative arbiter it is often more likely to be the party suffering the damage that has to pay than the polluter. A coalition of a limited number of large players could make the 'free rider' problem manageable.

- The correlation between efficiency and distribution. Market forces require a distribution of emission rights. Zero-sum distribution issues are typically very difficult to achieve. This is the case in advance here because with climate policy the allocation requires that most efforts take place in developing countries, whereas the costs of those efforts must be borne to a disproportionate extent by developed countries.

\subsubsection{CONDITIONS FOR EFFECTIVE COORDINATION}

The literature devotes a good deal of attention to the conditions for effective coordination, chiefly with a view to constructing comprehensive international treaties in the aftermath of Kyoto. All manner of classifications and subcriteria create a great deal of diversity, but using a variant of Aldy et al. (2003), seven frequently recurring criteria can be distinguished, which show a mutual correlation and which in part are strongly mutually competitive 
- Dynamic efficiency refers to an intertemporal global choice issue. The choice establishes the goals and concerns the distribution of resources between mitigation, adaptation, technology policy and other public and private expenditure.

- Environmental effectiveness is concerned with efficacy. The policy must contribute to the achievement of the above goals, something that is less self-evident than it seems.

- Cost-effectiveness requires that the goal is achieved with the minimum investment of resources. In the long term, cost-effectiveness also encompasses the intertemporal choice between innovation (new (breakthrough) technologies in OECD countries) and diffusion (existing technologies in poorer countries).

- Fairness refers to a distribution of benefits and costs, responsibilities and support that is perceived as fair. Article 3.1 of the UNFCCC, which speaks of 'common but differentiated responsibilities' plays a large (perhaps too large) role here.

- Flexibility is needed in the light of the growing knowledge about the climate and the technological possibilities, but limits the stringency of long-term agreements and thus creates uncertainty about future obligations.

- Broad participation brings the policy choices closer to the global prosperity ideal and is also to some extent a condition for perceived fairness. Broad participation competes strongly with efficacy, because effective measures are expensive.

- Objective monitoring and enforcement are necessary in order to make efforts visible to the other parties, a necessary condition for coordinated efforts.

\subsection{THE PRINCI PAL PLAYERS: INTERESTS AND POLICY}

The opportunities for effective negotiations are determined by the interests of the biggest players. The top six producers (US, EU-25, China, Russia, Japan and India) account for more than two-thirds of the total $\mathrm{CO}_{2}$ emissions. In terms of land use, Indonesia and Brazil are also important producers of greenhouse gases (GHGS). It is in these eight countries/regions that the greatest reduction potential lies and, because the group contains the large economies, it is also where most of the likely damage will take place and where there is the greatest capacity for taking measures. In the medium term (up to 2030) these eight countries will determine the course of events. The interests will be largely determined by the energy structure of their economies, and the existing energy structures will exert a dominant influence on the climate policy pursued in the coming decades. Section 5.3.1 therefore looks at the diversity of energy structures in the world's eight largest emitters of greenhouse gases. In addition, the individual interests and current climate policy of the United States (section 5.3.2), China (5.3.3) and Europe (5.3.4) are explored.

\subsubsection{DIVERSITY IN THE ENERGY STRUCTURE OF THE BIG EIGHT}

Table 5.1 brings together key figures for the above eight (groups of) countries for 2002 
and 2030 based on the authoritative IEA World Energy Outlook (2004). The IEA calculated the energy-related annual $\mathrm{CO}_{2}$ emissions for 2030 in two ways: without additional climate policy (but with energy efficiency trends, etc.) (second column) and with specified additional climate policy (the Alternative Scenario) (third column). The percentages in column 3 represent the plausible reduction compared with the BAU scenario. The key figures are supplemented with a few more specific focus areas which can explain in more detail where the sensitivities lie and where opportunities for coordination occur.

Table 5.1 Key indicators for the interests of the major players

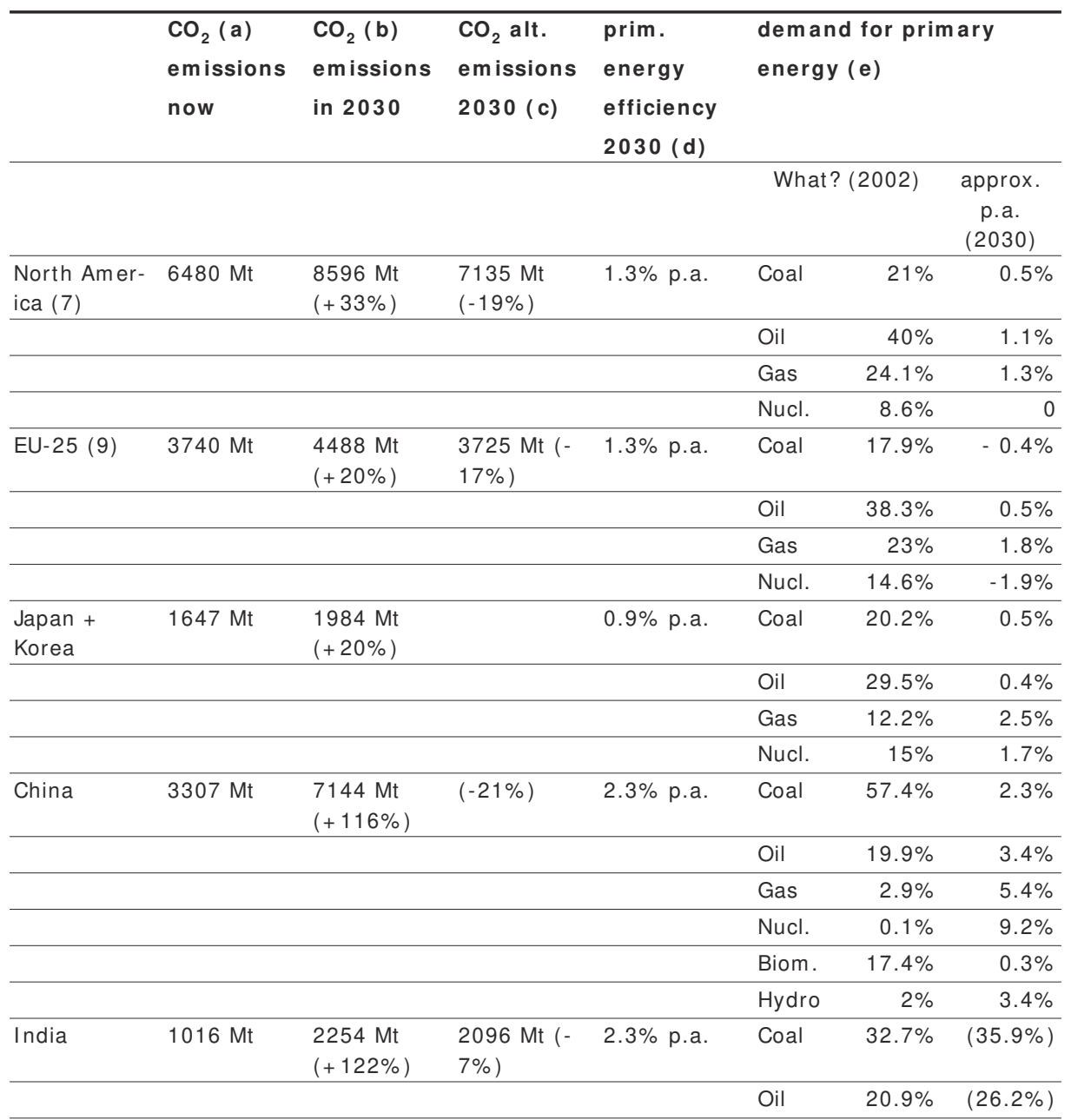




\begin{tabular}{|c|c|c|c|c|c|c|c|}
\hline & & & & & Gas & $3.6 \%$ & $(7.8 \%)$ \\
\hline & & & & & Nucl. & $0.2 \%$ & $(2.9 \%)$ \\
\hline & & & & & Biom. & $34.5 \%$ & $(21.3 \%)$ \\
\hline & & & & & Hydro & $6.4 \%$ & $(5.8 \%)$ \\
\hline & & & & & \multicolumn{2}{|c|}{ (rounded off) } & (shares) \\
\hline \multirow[t]{6}{*}{ Brazil } & $302 \mathrm{Mt}$ & $\begin{array}{l}655 \mathrm{Mt} \\
(+120 \%)\end{array}$ & $\begin{array}{l}547 \text { Mt (- } \\
18 \%)\end{array}$ & $0.5 \%$ p.a. & Coal & $6.9 \%$ & $1.9 \%$ \\
\hline & & & & & Oil & $46.8 \%$ & $2.4 \%$ \\
\hline & & & & & Gas & $9.6 \%$ & $5.8 \%$ \\
\hline & & & & & Nucl. & $2.1 \%$ & $2 \%$ \\
\hline & & & & & Biom. & $24.5 \%$ & $1.2 \%$ \\
\hline & & & & & Hydro & $13.3 \%$ & $2.2 \%$ \\
\hline \multirow[t]{4}{*}{ Indonesia } & $303 \mathrm{Mt}$ & $\begin{array}{l}783 \mathrm{Mt} \\
(+158 \%)\end{array}$ & & & Coal & $12 \%$ & $4.6 \%$ \\
\hline & & & & & Oil & $36 \%$ & $2.9 \%$ \\
\hline & & & & & Gas & $21 \%$ & $3.5 \%$ \\
\hline & & & & & Biom. & $26 \%$ & $0.2 \%$ \\
\hline \multirow[t]{4}{*}{ Russia } & $1488 \mathrm{Mt}$ & $\begin{array}{l}2062 \mathrm{Mt} \\
(+39 \%)\end{array}$ & $\begin{array}{l}1879 \text { Mt (- } \\
17 \%)\end{array}$ & $\begin{array}{l}\text { approx. } \\
1.5 \% \text { p.a. }\end{array}$ & Coal & $17 \%$ & $0.3 \%$ \\
\hline & & & & & Oil & $21 \%$ & $1.6 \%$ \\
\hline & & & & & Gas & $53 \%$ & $1.5 \%$ \\
\hline & & & & & Nucl. & $6 \%$ & $0.9 \%$ \\
\hline
\end{tabular}

Source: All data (calculated) from IEA, 2004, World Energy Outlook and Annexes. Notes: (a) 2002, energy-related CO2 emissions; (b) ditto, in IEA Alternative Scenario (analysis on pp. 387-397); N.B.: decline compared with standard scenario in previous column; (d) primary energy efficiency, improvement per year up to 2030 (in \%); (e) electrical imports = primary demand for energy, by energy sources, showing first the shares in 2002 and in the adjacent column the expected annual growth in $\%$ now up to 2030 with the exception of India; (f) North America = US, Mexico and Canada, because it is only in this combination that all data are comparable; $(\mathrm{g})$ the decline here is for OECD Europe, which does not correspond exactly with the EU-25.

\section{Focus areas}

- oil prices high (including petrol prices), good for coal (and nuclear?)

- net imports of total energy consumption double from $14 \%$ to $27 \%$

- renewable energy (ex. hydro) from $4.3 \%$ to $6.7 \%$ (2030)

- switch back to coal weaker (than in US) because coal has (also) become more expensive, partly due to long transport distances

- renewable energy (ex. hydro) at most $9.7 \%$ in 2030

- extreme import dependency for oil (94\% of demand in 2030) and gas (explosive increase from $49 \%$ to $81 \%$ )

- extreme import dependency for oil, gas and coal

- nuclear energy increases from $15 \%$ to $18 \%$ (2030)

- renewable energy (ex hydro) only $4 \%$ in 2030 , despite policy 
- $\quad$ energy saving is top priority in the latest five-year plan

- import dependency for oil (from $28 \%$ in 1998 through $37 \%$ in 2003), to $74 \%$ in 2030

- financing (\$2000 billion) of the increase in the supply of electrical not hampered by (high) domestic savings, but by other major obstacles

- coal dominates as input for electricity (trebling in TWh up to 2030), at 77\% in 2002 and $72.4 \%$ in 2030; the question is whether that will not go even higher if oil/ gas prices remain high

- lots of coal, but of poor quality

- biomass accelerates electrification in isolated areas

- for cars, biofuel and CNG are important and actively promoted

- local pollution very serious (opportunities for co-benefits?)

- hydro dominates (electricity supply) (80\% in 2002); drought risk

- biomass significant for industry and transport (cars from $13 \%$ to $16 \%$ in 2030 )

- low carbon inten sity very favourable, but the gradual improvement in energy intensity is weak - not dependent on oil/gas imports (if anything, improves up to 2030)

- climate policy to date strict, partly due to state monopolies and strict energy regulation; is becoming freer/open

- N.B..: if land-use CO2 is included, Brazil does have high immissions

- despite a strong desire in Russia to save (37\%), it may not be possible to finance the required energy investments ( $\$ 935$ billion up to 2030 )

- export shares of coal, gas, oil first increase, then decrease up to 2030

- carbon intensity a great concern: CO2 emissions per unit GDP more than double those in the OECD and developing countries; per capita emissions extremely high

- high priority (local and global) environmental policy, including for nuclear

- Kyoto and J.I. will to some extent force environmental policy

The variation between the players is enormous. This at once provides the most important lesson in exercises of this sort: it is important that the countries of the EU do not treat the interests and drivers of other countries and regions too lightly. The alternative scenarios with a fairly strict climate policy produce results. Evidently it is possible to pursue climate policy outside Kyoto, because according to the IEA the reduction under the Alternative Scenario compared with a BAU scenario is of the same order in the United States as in the EU and China. However, the bad news is that when everything is taken together, even under the Alternative Scenario $\mathrm{CO}_{2}$ emissions continue to grow strongly up to 2030 .

In each of the Big Eight (with the exception of Brazil), a steady improvement in energy efficiency is a key driver of emission reduction. Many of these improvements are achieved by incorporating new technologies into new investments in power stations, industrial processes and transport. Diffusion and influencing investment flows (and their timing) should therefore occupy a central position in all climate policy.

Nuclear energy is under pressure only in the EU and, to some extent, the US. Elsewhere, nuclear energy is promoted to a greater or lesser extent (except in Indone- 
sia). China, in particular, sees nuclear energy as a secondary resource (alongside the emphasis on coal) for achieving security of energy supply. Within the EU there is a wide diversity of views - and therefore of actions - on nuclear energy. Nuclear energy can and will make an important contribution to global mitigation in the next 30 years, with or without the Netherlands, but its share in the primary energy supply is unlikely even to remain at its present level globally, despite the building of new power stations.

Demand for oil for transport has risen particularly strongly in China. High demand and limited production capacity are driving the price upwards, and this is (further) increasing the pressure to use coal for electricity generation. China has a coal-based economy which can consequently pose a threat to coordinated mitigation (unless carbon capture and storage (CCS) can be introduced at reasonable cost). Other countries such as the US, Canada, Ukraine, South Africa, India and Russia are coal-based economies to a greater extent than the eu: coal is cheap and plentiful there and is therefore more widely used.

\subsubsection{THE POSITION OF THE UNITED STATES}

\section{Structural characteristics of the American economy}

Table 5.1 shows that the structure of the US economy differs considerably from that of Europe. Half of all electricity generation is based on coal, of which there are sufficient reserves to last at least two hundred years. The need for energy security and the prices of oil and gas make exploitation of those coal reserves almost inevitable. CCS is likely to be applied at best gradually, and only if it has little or no impact on America's competitiveness. A fifth of America's electricity is generated using nuclear power, but the number of nuclear power stations has not increased for almost 25 years, partly because of the huge capital investments involved. The US also has a carbased economy with low fuel efficiency and little public transport. The transport sector consumes more energy than industry and is growing faster. Consumption will rise by $1.3 \%$ per annum up to 2030 . Energy security has a very high priority for the American superpower, but is currently under great pressure. According to the IEA, America's dependence on external energy will grow from $14 \%$ in 2002 to $27 \%$ in 2030.

\section{Current climate policy in the US}

The American people are not indifferent to climate change and GHGS, but there is a cultural difference compared with Europe. There is also a clear difference between the federal and state level and between individual states. On the East and West Coast there are states which are pursuing a progressive climate policy and which even want to set up an emissions trading system. At federal level, policy is dictated by the unanimously adopted Bird/Hagel resolution (1997), in which the Senate declares its support for a mitigation policy that attaches two conditions to international obligations, namely "no substantial harm to the US economy" and the notion that all UNFCCC countries (ulti- 
mately, but laid down in advance) must comply with mitigation obligations. Adaptation to climate change is (rightly or wrongly) seen as a serious option in the US.

The position of the Bush administration differs to only a limited degree from that of earlier governments. The Kyoto Protocol was formally rejected by President Bush in 2002. In its place, American climate policy has three main tracks:

- Mitigation based on an intensity objective: $18 \%$ emission reduction per unit GDP in the period 2002-2012.

- Great faith in technological solutions and an extensive science and technology development programme.

- International cooperation focused on (clean) economic growth and technology development.

\subsubsection{THE POSITION OF CHINA}

\section{Structural characteristics of the Chinese economy}

China is in the process of passing the EU-25 in the ranking of (absolute) $\mathrm{CO}_{2}$ polluters, making it the world's biggest polluter after the United States. China's share in global $\mathrm{CO}_{2}$ emissions is set to grow from $14 \%$ in 2002 to $19 \%$ (of a much greater total) in 2030. Primary energy consumption in 2002 was accounted for by coal (57\%), oil $(20 \%)$ and biomass (17\%). Chinese biomass is almost exclusively the product of underdevelopment. Coal will continue to dominate, especially in electricity generation, because Chin a has extensive reserves and coal is cheap. The country's economic structure differs markedly from that of the EU and the US. In 1998, industry produced $75 \%$ of China's $\mathrm{CO}_{2}$ emissions and transport only $9 \%$. Industry will remain the most important sector for the time being, though (car) transport is expected to increase explosively. In view of the great concerns about the rapidly increasing dependence on imported energy, China is looking to diversify its energy supply. In order of growth rate (from a small base), this means nuclear energy ( $9.2 \%$ per annum), natural gas (5.4\% per annum) and major hydropower projects (3.4\% per annum).

\section{Current climate policy in China}

China has ratified the UNFCCC and the Kyoto Protocol, but neither imposes any quantitative obligations on China. This does not however mean that there is no climate policy. Energy efficiency is improving rapidly by $1.5 \%$ per year, as a result of all manner of direct and indirect policy. China's priority is on economic growth and external energy supply security. However, the country has been found willing to invest heavily in noregret policy of all kinds in line with these priorities. In addition, central government is trying to introduce the principle of 'the polluter pays' to combat the major local environmental problems, in the face of resistance from local interests and widespread corruption. Fuel standards have been introduced in the transport sector, which in terms of their strictness are midway between the American and the more stringent EU standards. 


\subsubsection{THE POSITION OF THE EUROPEAN UNION}

This section is concerned with the strategic position of the EU. The actual climate policy pursued by the EU was outlined earlier, in chapter 2. The EU has assumed the role of leader; in 1996, a year before the Kyoto Protocol, the European Council of government leaders adopted the $2^{\circ} \mathrm{C}$ target., reaffirming it in March 2005. This selfdeclared leadership has been repeatedly tested as other major players have pulled out (most notably the US in Kyoto) or failed to pull their weight completely (e.g. not one single firm obligation under the Kyoto Protocol for developing countries, including China and India, but also for less poor 'developing countries'). During the 2001 European Council in Gothenburg, the definitive American rejection of the Kyoto Protocol (shortly before the Council) was met with a solid enforcement of the policy, rooted explicitly in the credibility of the European leadership. Table 5.2 summarises the main strategic principles which determine current EU climate policy.

The eu's emissions trading system is a thoroughly worked out apparatus which serves as an example to the world. In term s of $\mathrm{CO}_{2}$ mitigation, however, it remains a modest finger exercise for the moment. Partly because of this, the anticipated $\mathrm{CO}_{2}$ price will not be high enough to provide an impetus for new technology, but will be high enough to force short-term improvements in energy efficiency, etc.

\section{Table 5.2 Strategic principles of European clim ate policy}

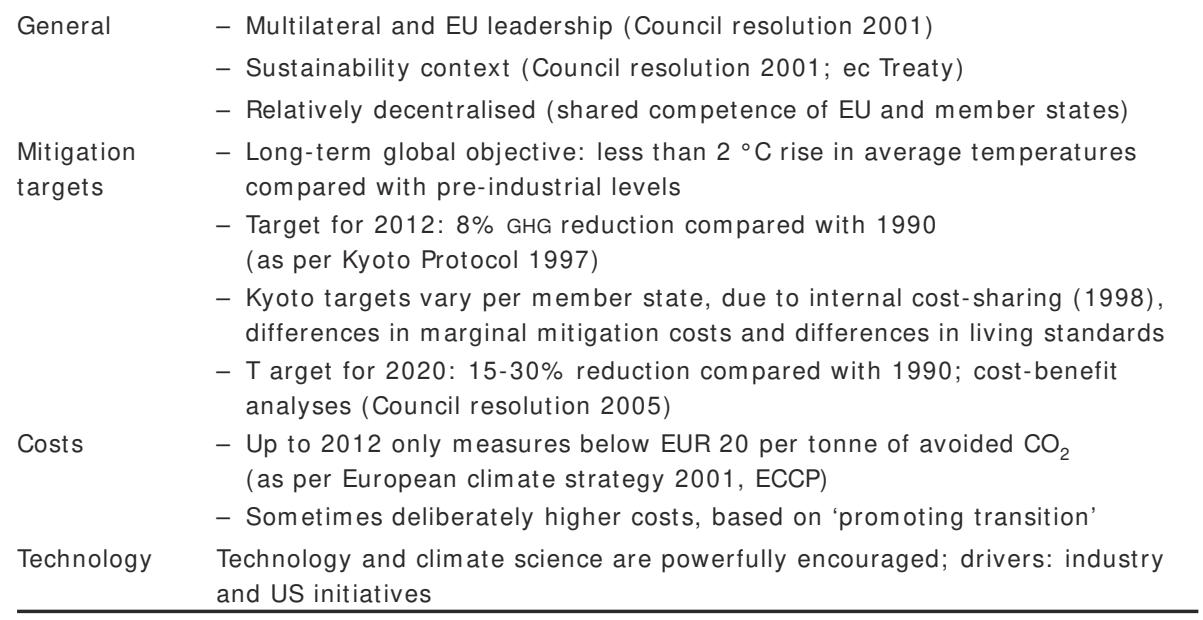


5.3.5 THE POSITIONS COMPARED

Table 5.3 Interests and positions of three major climate players

\begin{tabular}{|c|c|c|c|}
\hline & United States & China & European Union \\
\hline $\begin{array}{l}\text { I mportance of } \\
\text { climate policy }\end{array}$ & $\begin{array}{l}\text { - It's important } \\
\text { - Differences } \\
\text { between fede- } \\
\text { ral and state } \\
\text { authorities }\end{array}$ & $\begin{array}{l}\text { - High growth is first } \\
\text { priority }\end{array}$ & $\begin{array}{l}\text { - Precautionary principle } \\
\text { is central } \\
\text { - Leadership despite } \\
\text { costs }\end{array}$ \\
\hline Targets & $\begin{array}{l}\text { - } \text { Mitigation } \\
\text { via intensity } \\
\text { targets } \\
\text { - Cost-effectiven- } \\
\text { ess is central }\end{array}$ & $\begin{array}{l}\text { - Local environ- } \\
\text { mental pollution is } \\
\text { urgent problem to } \\
\text { be addressed }\end{array}$ & $\begin{array}{l}-2^{\circ} \mathrm{C} \text { target is fairly } \\
\text { sacrosanct }\end{array}$ \\
\hline Resources & $\begin{array}{l}\text { - Technologi- } \\
\text { cal solutions } \\
\text { preferred }\end{array}$ & $\begin{array}{l}\text { Polluter beginning } \\
\text { to pay because } \\
\text { local action has } \\
\text { co-benefits for } \\
\text { climate }\end{array}$ & $\begin{array}{l}\text { - Carbon markets and } \\
\text { emissions trading are } \\
\text { the main instruments } \\
\text { - Technology policy is } \\
\text { supplementary } \\
\text { - Optimism on renewa- } \\
\text { ble energy } \\
\text { - Growing focus on } \\
\text { cost-effectiveness, } \\
\text { including for measu- } \\
\text { res outside emissions } \\
\text { trading }\end{array}$ \\
\hline View on Kyoto & - Rejected & $\begin{array}{l}\text { - Free ride } \\
\text { - No obligations, but } \\
\text { CDM opportunities }\end{array}$ & $\begin{array}{l}\text { - Finger exercise } \\
\text { - Absolute reduction } \\
\text { targets, in } 2020 \\
\text { commitment to }-15 \% \\
\text { to }-30 \%\end{array}$ \\
\hline $\begin{array}{l}\text { Conditions for } \\
\text { coordination }\end{array}$ & $\begin{array}{l}\text { - No harm to US } \\
\text { economy } \\
\text { - Developing } \\
\text { countries must } \\
\text { also take part }\end{array}$ & $\begin{array}{l}\text { - Per capita emissi- } \\
\text { ons are a key issue } \\
\text { - Commitment is } \\
\text { so far beyond the } \\
\text { horizon that there } \\
\text { are no formal } \\
\text { conditions }\end{array}$ & \\
\hline Adaptation & - Serious option & $\begin{array}{l}\text { - Not yet really } \\
\text { considered }\end{array}$ & $\begin{array}{l}\text { - Growing attention, } \\
\text { including support to } \\
\text { poor countries }\end{array}$ \\
\hline
\end{tabular}




\begin{tabular}{|c|c|c|c|}
\hline $\begin{array}{l}\text { Security of } \\
\text { energy supply }\end{array}$ & $\begin{array}{l}\text { - High priority } \\
\text { - Coal is plentiful } \\
\text { - Nuclear energy } \\
\text { a serious option }\end{array}$ & $\begin{array}{l}\text { - Most important } \\
\text { goal after growth } \\
\text { - Coal-based } \\
\text { economy } \\
\text { - Diversification } \\
\text { attempts via hydro- } \\
\text { power and nuclear } \\
\text { energy } \\
\text { - Growth of oil } \\
\text { imports due to } \\
\text { number of vehicles }\end{array}$ & $\begin{array}{l}\text { - Emerging priority } \\
\text { - Nuclear energy some- } \\
\text { times discredited } \\
\text { - Limits of renewable } \\
\text { energy becoming visi- } \\
\text { ble }\end{array}$ \\
\hline $\begin{array}{l}\text { Starting } \\
\text { position }\end{array}$ & $\begin{array}{l}\text { - High per capita } \\
\text { emissions } \\
\text { - Medium emis- } \\
\text { sions per unit } \\
\text { GDP } \\
\text { - Medium econo- } \\
\text { mic growth }\end{array}$ & $\begin{array}{l}\text { - Low per capita } \\
\text { emissions } \\
\text { - High emissions per } \\
\text { unit GDP } \\
\text { - Very high economic } \\
\text { growth } \\
\text { - Demography is a } \\
\text { relatively unexplo- } \\
\text { red brake on emis- } \\
\text { sions growth }\end{array}$ & $\begin{array}{l}\text { - High per capita emis- } \\
\text { sions } \\
\text { - Low emissions per unit } \\
\text { GDP } \\
\text { - Low economic growth }\end{array}$ \\
\hline
\end{tabular}

Source: WRR

\subsection{INSTITUTIONS AND STRATEGIC OPTIONS FOR GLO- BAL CLI MATE POLICY}

Section 5.4.1 draws lessons from a comparison between the climate problem and the ozone problem. Section 5.4.2 indicates how these lessons can be used as input to build on the UNFCCC. As the climate problem cannot be solved by an emissions ceiling alone, a 'multicoloured flexibility' is needed (section 5.4.3), in which international climate initiatives can be made visible and coordinated, as well as an improvement in the institutional dimension (section 5.4.4). The flipside of multicoloured flexibility is an absence of obligation. Coalition formation, and leadership of and within coalitions (section 5.4.5) are needed to increase the sense of obligation.

\subsubsection{MONTREAL VERSUS KYOTO}

The Montreal Protocol on Substances That Deplete the Ozone Layer (1988) has been a success. There are clear differences and correspondences compared with the climate problem.

\section{Cost-benefit analyses}

Both the ozone problem and the $\mathrm{CO}_{2}$ problem are global atmospheric problems which cause damage and require coordinated mitigation efforts. However, the cost-benefit analyses for ozone and for $\mathrm{CO}_{2}$ are very different, both in terms of magnitude and timeframe. With the ozone problem, the OECD member states were able to achieve 
sizeable net benefits from mitigation at individual country level in the relatively short term, without this requiring short-term efforts from non-OECD countries. The benefits of $\mathrm{CO}_{2}$ mitigation are much less clear-cut than with ozone and can be achieved only in the very long term. Major net benefits at individual country level are unlikely, because GHG emissions are diffused much more widely than emissions of gas propellants. It is clear that, without the commitment of developing countries, at some point in the future the mitigation benefits will be too small in relation to the costs to motivate OECD countries to take action. There is thus no unilateral option for OECD countries, as there was for ozone.

\section{Architecture of the Protocol}

There are five elements of the architecture of the Montreal Protocol which bolstered its efficacy:

- Global participations. From the first variant of the Montreal Protocol, emission ceilings were compulsory for all participants. This was also possible (in contrast to the Kyoto Protocol) because the timeframe was more compact and financial compensation for developing countries remained affordable.

- Compensation for the incremental costs for poor countries. This is at least a hundred times more expensive with the climate problem than with the ozone problem. Moreover, the costs of this compensation are rising strongly as a result of the anticipated economic growth of developing countries.

- Time consistency for investments. The credibility of the emission ceilings under the Montreal Protocol was great enough to enable long-term investments to be based upon it. By contrast, the validity of the Kyoto Protocol is limited (up to 2012 ), with uncertainty as to what will happen thereafter.

- Trade sanctions. The Montreal Protocol incorporated credible trade sanctions against non-signatories with regard to specific substances and products. $\mathrm{CO}_{2}$ is much less specific.

- Compulsion. The Montreal Protocol was reinforced in 1992 by a 'carrot and stick' approach. The Kyoto Protocol has only limited instruments to enforce compliance.

\subsubsection{BUILDING ON THE UNFCCC}

\section{Goal and principles}

Almost 190 countries have signed up to the UNFCCC, an indication that the main objective and principles enjoy virtually universal support. The ultimate objective is to prevent human activity from damaging the climate and to slow down the rate of change sufficiently to enable ecosystems to adapt. More operational principles can be based on the tenet of 'common but differentiated responsibilities', such as 'the polluter pays' and differentiation by ability to mitigate and to take account of special vulnerabilities (e.g. in poor countries). The focus on the future ('for the benefit of present and future generations') can give rise to principles of environmental efficacy and efficiency, 
as well as a recognition that economic growth in poor countries is a legitimate priority. The precautionary principle rules out the interpreting of uncertainty as a compelling reason not to pursue policy. The GATT compatibility prevents climate policy being misused as a means of erecting arbitrary trade barriers.

\section{Obligations}

Mitigation obligations apply under the Kyoto Protocol only for the Annex 1 countries. There is no timeframe or mechanism for future obligations. Also, there are no sanctions for failure to comply with most of the obligations arising either from the Kyoto Protocol or the UNFCCC. Reporting requirements are however included which could lead to exchange, consolidation and possibly open debate on each other's climate policy. The reports are intended to lead to an external evaluation of the policy pursued. So far, evaluation (among other things under Article 4.2) or enforcement have failed due to an impasse between Annex 1 countries and other countries. Combined with the weak reporting requirements, this is currently the Achilles heel of the UNFCCC. Weak obligations to some extent fit in with the weak mechanism for dispute settlement incorporated in the UNFCCC. The combination of these two could be interpreted as a sign of a wide gap between principles and effective obligations.

\section{Organisation of the negotiations}

The organs of the international coordination of climate policy are partly formal and partly informal. Figure 5.1 shows the most important bodies in both guises. The UNFCCC is not a standing organisation; progress is managed by the Conference of the Parties (COP) which meets once or twice a year and in which all countries participate. The meetings of the COP are fairly unproductive for three reasons: they are too big; the cop largely has the function of a forum which is used for conveying messages relating to domestic politics; and the un model used, which gives everyone a vote on everything, means that the COP lacks any real structure. 
Figure 5.1 Climate negotiations: structure and groupings

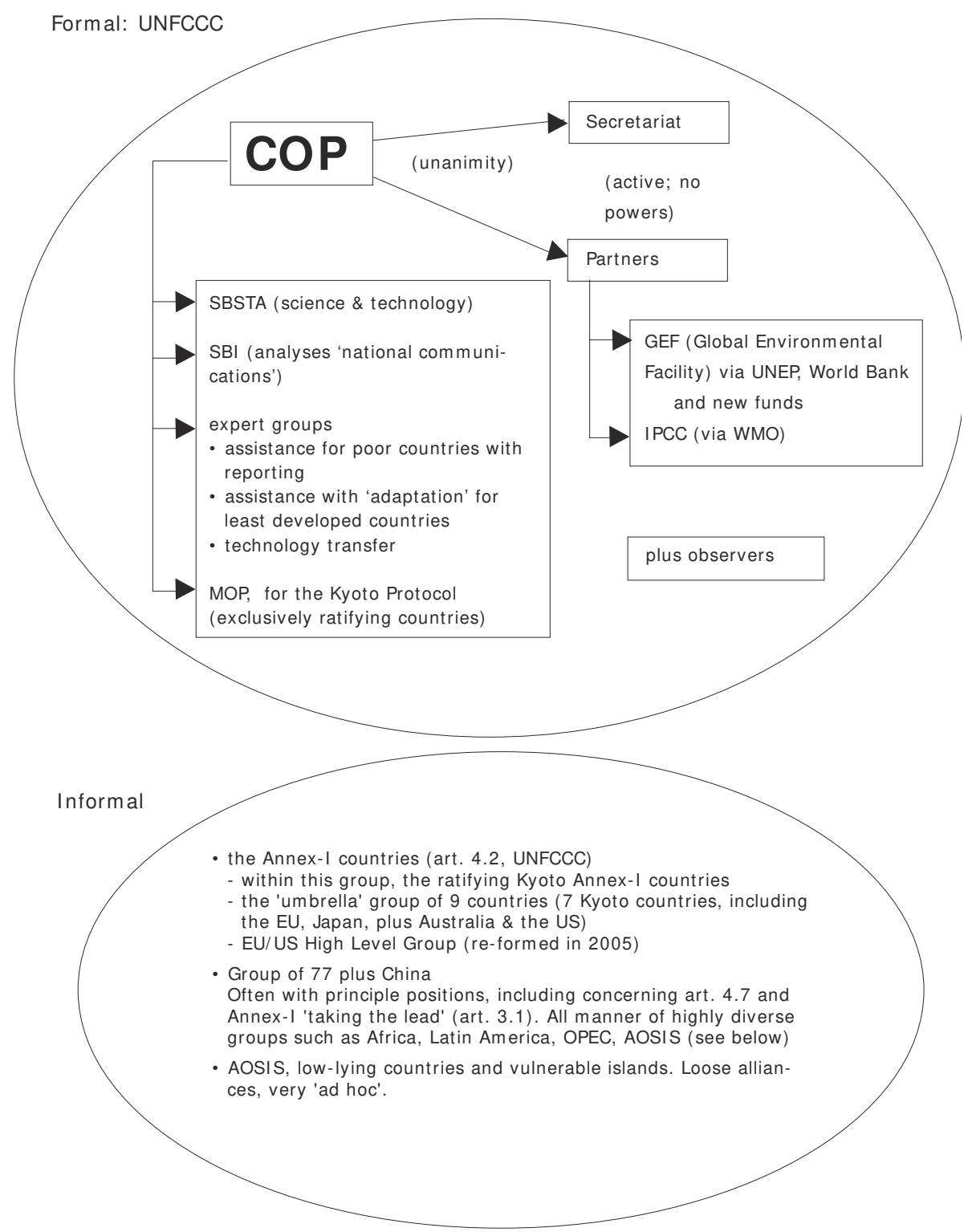




\section{Thinking outside Kyoto without abandoning Kyoto}

The post-Kyoto negotiations in the Meeting of the Parties (MOP) offer more promise than the COP, given the legal obligations and the precision of the Protocol. The effectiveness of the COP could be improved if cooperation incentives were built into the organisation based on mutual interests and aimed at encouraging problem-ownership by the parties. The key will be effectively negotiating adequate obligations of all kinds over a longer timeframe within the framework of the UNFCCC, and then actually enforcing those obligations. 'Multicoloured flexibility' (section 5.4.3) will be an essential part of this, but there is also an institutional dimension which requires improvement (section 5.4.4).

\subsubsection{MULTICOLOURED FLEXI BILITY}

Coordination means that parties take on related obligations. Figure 5.2 shows that a wider diversity of policy commitments is possible. The left half of the figure sums up three main choices, which are separate from the nature and content of the commitments. The right-hand side of the figure indicates how mitigation obligations can be examined. 
Figure 5.2 Key points of a global climate policy

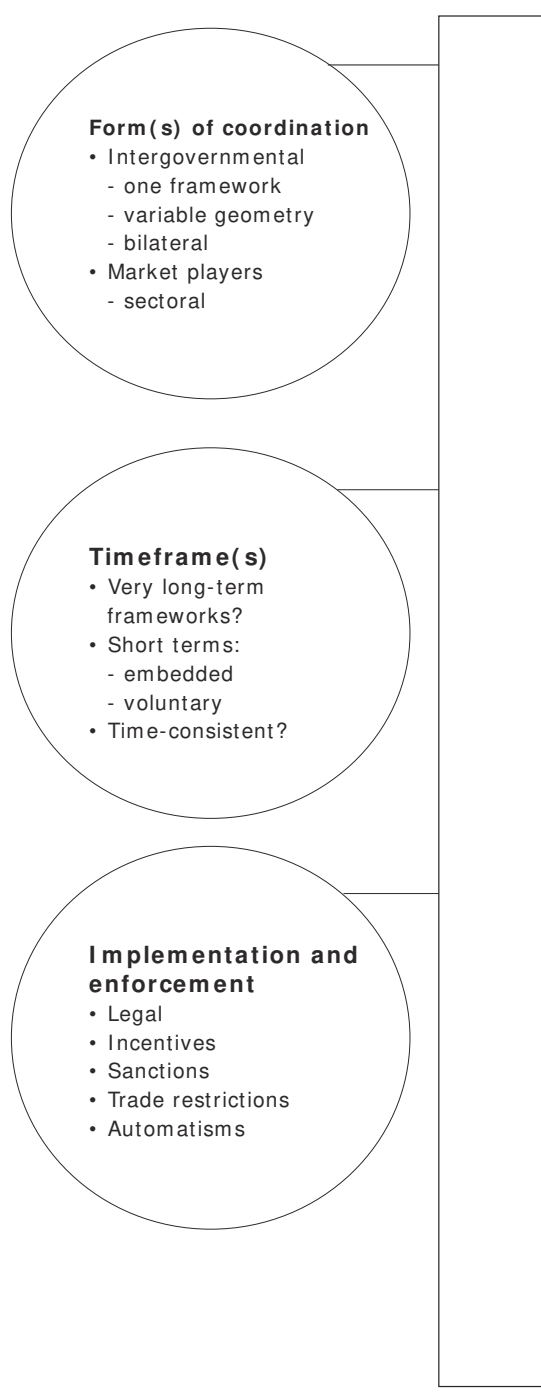

Source: WRR

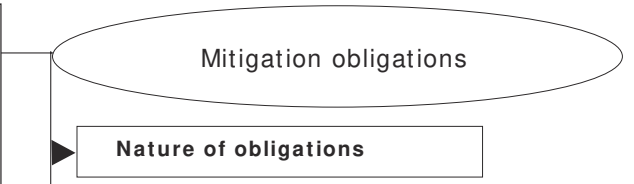

- All kinds of policy categories negotiated multilaterally

- (Rational) variable long-term pathway, multilateral, leading to cumulative obligations over time and to development levels

- Menu, more or less freely chosen

- Voluntary, each policy, transparency and the monitoring (bottom-up)

\section{Categories of obligations (catalogue)}

- Absolute, quantitative targets (as per Kyoto)

- Intensity targets (carbon, energy consumption)

- 'Only benefits' (no lose) targets, in stricter individual or collective framework

- Sectoral or (zero-emission) technology obligations

- Emissions trading with maximum prices (safety value)

- (Harmonisation of) national climate policy (= PAMs) such as world carbon taxes, standards and technology protocols

- Financial transfers, including conditional transfers to poor countries, or via a world climate fund

\section{Hardness of obligations}

- Gradation of stringency, over time according to develop ment level, etc.

- Or initially only 'inviting' perspective for poor countries (and US?)

\section{Differentiation and cost-sharing}

- All kinds of differentiation criteria

- Obligations by 'status' (graduation index)

- Differentiation according to countries, hardness, time

- Cost-sharing driven e.g. by principles such as per capita emissions, cumulative obligations, marginal litigation costs or established procedures

- Possibly link cost-sharing to support for 'adaptation'

\section{Main choices}

In the first place, coordination can be effected both via governments and via the market. The two approaches are not mutually exclusive, but complement each other. Based on the common framework, the UNFCCC, different alliances may arise in a variable Asia Pacific Partnership of the US, India and China. In addition, market players are able and often willing to agree on standards at sectoral level. Market forces do 
not always have to be driven by the government. Trade sanctions can under certain conditions supplement international environmental treaties. Experience has shown that the trade context can be successfully used via the mechanism of issue linking. For example, Russia owes the support it received from the EU for its WTO membership partly to the fact that it signed up to the Kyoto Protocol. Long-term timeframes are important because of the long-term nature of the problem and a certain optimisation of the mitigation strategy, but cannot always be negotiated in advance. Without attention for monitoring and enforcement, finally, coordination cannot be achieved.

\section{Nature and content of the obligations}

Multilateral treaties need not, or not exclusively, be about absolute reduction targets. In such a framework, a second Kyoto Protocol could form part of a much broader web of protocols or commitments. The distribution of the costs and the location where cost-effective mitigation takes place need not coincide. In addition, when it comes to the nature of the obligations there is no objection to more or less freely chosen menus of mitigation methods at UNFCCC level.

Figure 5.2 distinguishes seven categories of obligations. Absolute, quantitative targets such as those set out in the Kyoto Protocol have pertinent advantages, such as clarity about the result and the possibility of achieving cost-effectiveness through emissions trading. It may also be possible to link an international carbon market to businesses in countries (such as the US) which have not entered into any absolute commitments (see Egenhofer 2005, in CEPS 2005). Absolute targets are made more acceptable if a safety valve is built in in the form of a maximum carbon price. Intensity targets are aimed at reducing carbon use per unit GDP (decarbonisation) or energy consumption ('decoupling'). GDP growth can partly or fully cancel out the reduction in emissions; this is the case in China and the us. Sectoral targets are appropriate for involving the private sector. Positive incentives which rule out loss (no-lose options) are suitable for bringing in poor countries. Gradual harmonisation of national policy in the form of policies and measures (PAMS) also offers a low-threshold option. Financial and nonfinancial transfers are also possible which could operate bilaterally, via technology treaties or via a world climate fund.

The third perspective is that of the hardness of the obligations. The UNFCCC recognises the priority that developing countries attach to economic growth. It is therefore important to create some clarity on the question of when a developing country undergoes the transition to a modern industrialised nation. Multistage approaches try to objectify these transitions, but our definition of criteria for graduation has so far not worked in the GATT.

The fourth perspective, finally, relates to the distribution of costs. The principle of 'common but differentiated responsibilities' can be operationalised in many different ways. 


\subsubsection{INSTITUTIONALISATION OF GLOBAL COORDINATION}

It can be seen from figure 5.1 on the structure of the present climate negotiations and the operation of the UNFCCC that there is in reality virtually no structure. The configuration is geared almost entirely to negotiations in the COP, albeit with technical support from bodies such as the Subsidiary Body for Scientific and Technological Advice (SBSTA), the Subsidiary Body for Implementation (SBI) and expert groups, in addition to an active secretariat (though which has no competences and cannot take its own initiatives). There is no permanent organisation that is concerned at all levels with implementation, supervision, feedback, studies and options and thorough preparation of negotiations in the COP.

A limited, specific institutionalisation of the global coordination of climate policy could lead to noticeable improvements. This should not be seen as a 'miracle cure'; the conflicts of interest will remain in a more institutionalised setting and it will be necessary to negotiate at all kinds of levels on financial transfers, often painful adaptations or policy changes. The priority given to the substantive aspects discussed above will also have to continue, because institutionalisation alone is not a panacea.

The UNFCCC signatories could establish a World Climate Organisation (WCO), with a supreme ministerial council (WCO Council) carrying out final negotiations. The permanent organisation of the WCO would need to comprise a secretariat and a formal committee of permanent ambassadors to the WCO, answering to a Special Climate Council (SCC), which would offer permanent seats to the largest seven or eight polluters as referred to earlier and with rotating country members and a rotating presidency, with for example 15 SCC members in total. Although all kinds of informal coalitions could be formed for negotiations, responsibility for the direction and efficacy of the WCO would be clearly in the hands of the SCC. There would be a recognition of ownership, as it were. The permanent scc would offer every opportunity for coalition formation and initiatives to flourish in mutual interest. Moreover, the permanence of the missions in the secretariat would offer a much better guarantee of the ever more intensive administrative and technical implementation, monitoring, linking with current research and other issues.

\subsubsection{COALITION FORMATION AND LEADERSHIP}

Effective coordination is based on a common interest and on mutual benefit from the efforts of the negotiating partners. For negotiating partners with major interests, the value of their input is much greater than the transaction costs of their participation in the negotiations. Small coalitions with large interests can achieve common aggregated preferences for participants with minimal transaction costs. Interests are determined above all by the extent to which damage is suffered, the size of the potential emission 
reduction and the weight of the participants' own policy discretion. As coalitions must be stable in order to function credibly, they cannot be too large. Game theory teaches us that large groups of more or less similar countries have difficulty in achieving large, stable coalitions. Nonetheless, it is almost unimaginable that every continent will not have at least one country in such a coalition of the greats. A strong coalition can also exercise political power through its size and therefore limit the free rider behaviour of outsiders. It is therefore of cardinal importance that, even if this collective can be institutionalised in the SCC of a new WCO, the members of the collective see that they have a direct interest in cooperation within this small group. Ownership is essential.

Leadership is also possible and desirable within coalitions. If the differences in size and importance are extreme, that the leadership may be exercised by a single country or a close-knit group of countries (such as the eu). The leader indicates the urgency and the direction. This entails costs. In order to make its leadership credible, it is essential that the EU achieves its Kyoto obligations. The question of whether those obligations actually constitute effective climate policy in the light of the objective is less important in this regard. 


\section{A DUTCH AND EUROPEAN CLIMATE STRATEGY}

\subsection{MATE STRATEGY REQUIRES AMBITION AND REALISM}

An effective and efficient climate policy demands an unusual combination of realism and ambition: the realism starts from the existing situation, but is unable to break away from it sufficiently; the ambition focuses on what is needed, but without realism will turn out to be nothing more than building castles in the air.

There has been no lack of ambition in the past decade. The European Union (EU) has taken the lead by formulating its $2{ }^{\circ} \mathrm{C}$ target. Achieving this target means that, according to current insights, net global emissions of greenhouse gases (GHGS) must be so low by around 2050 that the stock of GHGS in the atmosphere stabilises at around 550 ppmv $\mathrm{CO}_{2}$ equivalents by the end of the century. This report shows that it is in principle possible to opt for global emission reduction routes which realise the required ambition. That is the good news.

However, the $2^{\circ} \mathrm{C}$ target is also an exceptionally demanding one. An assessment of which global strategy can actually be realised requires a sober assessment of the interests and policy priorities of all countries, and above all of a limited number of large polluters with different preferences from the eu, and certainly from the Netherlands. In the Council's view, the combination of high ambition and low realism could very easily drive up the costs without underpinning the global efficacy - and that is the only thing that matters for the climate. Simply waiting without ambition until other countries demonstrate leadership is neither in Dutch long-term interests nor in line with the evident preferences of the Dutch population.

The Council is concerned about both the efficacy and efficiency of Dutch climate policy. If we look at climate policy in the light of all manner of other important social objectives (such as health care, education, reducing world poverty and securing energy supplies), the situation becomes more complex. It then becomes necessary to make choices between, say, investing a euro now or in ten years' time in education in poor countries or spending that same euro on climate policy. These are difficult judgments to make given the great uncertainties. And the precautionary principle cannot replace those judgments. In other words, it would smack of tunnel vision if the ambitions and efforts in relation to climate policy were not placed in this broad social context.

Climate policy can only be effective if it is embedded in a global strategy for the long term. If European and Dutch policy is geared only to their own preferences, own timeframes and own interests, it will be ineffective and will simply drive up the costs. 
Moreover, climate policy is not synonymous with emission reduction; it involves a combination of adaptation, emission reduction and global coordination, and their mutual interrelationship over the longer term.

In this final chapter the Council sets out a climate strategy in which priority is given to efficacy and efficiency. No guarantees can be given, because so many players help determine the result over a very long period, because further technological progress will be required and because there are still great uncertainties regarding the climate. However, the following mandatory requirements can be identified as a minimum:

- The strategy must be global. Europe and Japan do not determine either global emissions or the global political agenda.

- There is a time horizon spanning several generations.

- Strategic insight is needed into the choices and priorities (in the light of costs and benefits) over that long period - and for the world as a whole, not just for the Netherlands or the EU.

- There is a need to be open to the preferences and interests of other major players.

These criteria for efficacy and efficiency set the framework for the central question addressed by this WRR report: How can the Netherlands, as a member of the European Union, pursue an effective climate policy from a global and strategic perspective? The three policy tracks needed for the most effective possible climate strategy are outlined in figure 6.1: adaptation, emission reduction and global coordination. 
Figure 6.1 Three policy tracks of an effective climate strategy

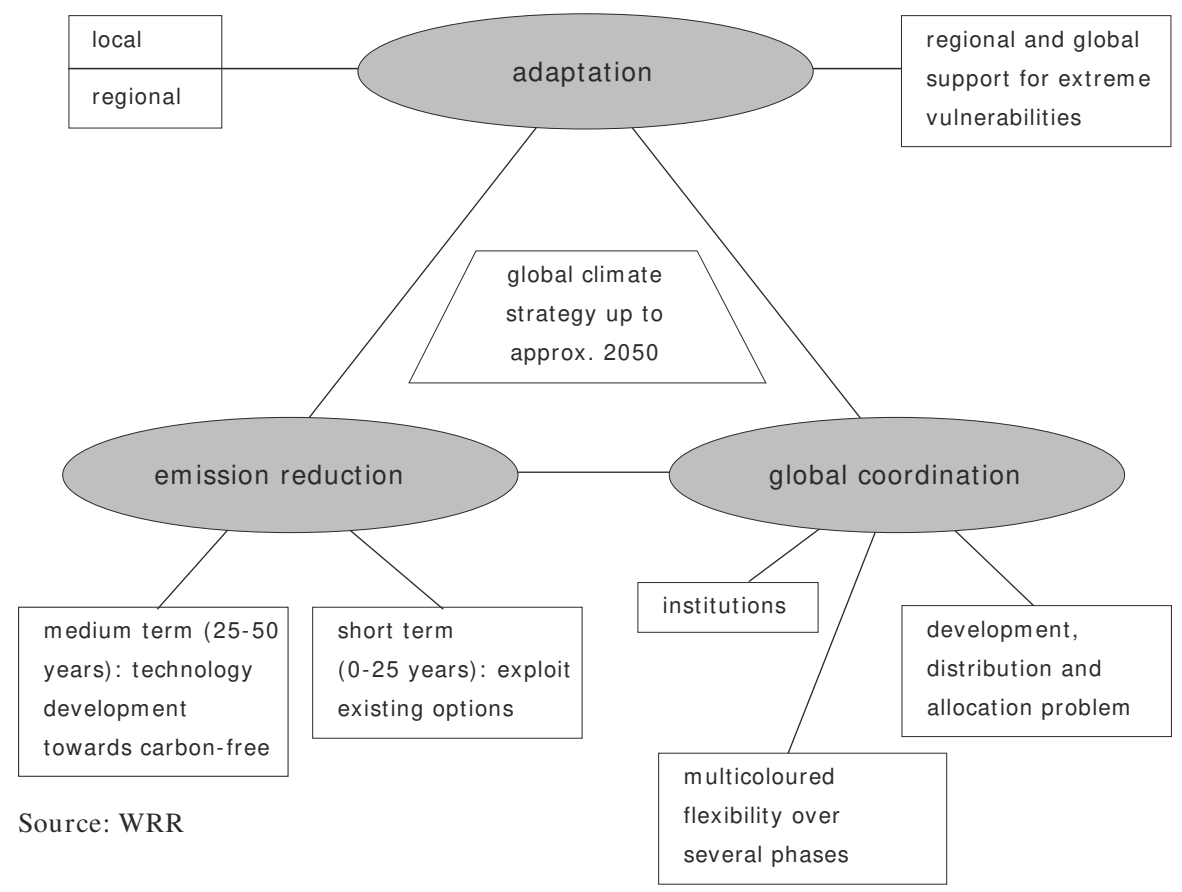

\subsection{HIGH PRIORITY FOR ADAPTATION}

\section{Reasons for high priority}

Adapting to a changing climate in the Netherlands is of great importance for four reasons:

- Even if a global emission reduction policy is successful, the climate will change in the next century.

- The credibility of a coordinated global emission reduction is currently low. Robust policy must explicitly take this into account, without becoming a self-fulfilling prophecy.

- Excessive vulnerability will undermine the negotiating position of Europe.

- The Netherlands has fallen behind in recent decades in securing cost-effective flood protection because the Delta standards have not been updated. This effect is greater than the anticipated effects of climate change, at least during the present century. 
The Council believes that in the climate strategy to date it has been too easily assumed that there is a lack of adaptive capacity, or that adaptation should be a second choice, because emission reduction will not (any longer) be enough to avoid climate change.

\section{Adaptation: a realistic option}

Adaptation policy cannot replace an internationally coordinated emission reduction strategy, but - at least for the Netherlands and for the next hundred years - is considerably simpler. Adaptation, where it is possible and provided it is not too expensive or disruptive, is locally attractive because the fruits of local efforts are enjoyed locally, whereas with emission reduction this is much less the case. Adaptation cannot be seen as an exclusively local process in all cases. The world community can strengthen the adaptive capacity of poor countries and will sooner or later have to accept vulnerabilities which are existential or disruptive for whole regions or peoples.

For the Netherlands, water management is crucial and needs to be given high priority in relation to flood safety. In addition, attention for natural assets and ecology is called for. Climate change not only brings threats for rural areas; it also brings opportunities, and some of those opportunities can be created in the wake of the measures to be taken.

\section{Recommendation 1}

The Council recommends that high priority be given to adaptation in a broad sense to a changing climate in the Netherlands. Adaptation is not an admission of defeat but is an effective form of problem-solving.

\section{The key is keeping open opportunities}

Measures to improve flood safety demand major investments and are long-term in nature. A phased approach can however be adopted for these investments. On the other hand, it is virtually impossible, or at least extremely expensive, to adopt a phased approach to setting aside areas for the flood safety policy. Unbridled urbanisation in areas which might be needed in the future for water management purposes could exact a heavy price later. The consequences of climate change for water management are anything but certain. It is not certain that areas set aside now will ever be used. Designating a dual purpose for these areas is therefore an obvious step. Setting aside areas for wet landscape functions could go hand-in-hand with designation for green usage (nature). However, such designation virtually rules out 'red' (construction) functions.

Measures to limit the risk of flooding required public support. Time and again measures that appear desirable at national level meet with resistance at local level which ultimately leads to a change in course in the national policy. Giving a higher priority to water management demands a stronger stance by national government which overrides the position of lower administrative layers. 


\section{Recommendation 2}

Areas of landscape must be set aside without delay for future water management. This means giving overriding importance to national over local priorities, as well as the necessary administrative changes to facilitate this. Since it is not certain that areas set aside in this way will actually be used, designating dual usage for water and nature, whilst ruling out construction, is a logical move. Major investments in flood safety can be made affordable by a phased approach over an extended period. Water management also requires international coordination in the major river basins.

\subsection{EMISSION REDUCTION: ROUTES AND TIMEFRAMES}

\section{Challenge: drastic reduction in carbon emissions by 2050}

The atmospheric concentration of GHGs that can be achieved by 2100 will be largely determined by the emissions in the next fifty years. This means that there is too little time to wait for a transition in the energy system if the EU's $2^{\circ} \mathrm{C}$ target is to be realistically achievable. It is a formidable challenge to ensure that net emissions reduce sufficiently over the next five decades, especially against the background of a growing world population and strong economic growth in developing countries. Growth has priority in these countries, and especially in those countries where the gulf compared with the wealthy nations is wider. This means that in the coming decades it is not only the wealthy countries but also the relatively poor countries which will increasingly have to reduce the carbon-intensity of their production. The emission reduction process is unlikely to have been completed after the next fifty years. It is therefore important to invest sufficiently in research and development (R\&D) and in niche applications in order to develop groundbreaking emission reduction options for the period after 2035-2050.

The Council identifies four main routes for a global emission reduction policy over the coming decades: (1) improved efficiency in primary energy consumption; (2) chan ging the energy mix (fossil energy, nuclear energy, modern renewable energy, etc.); (3) use of sinks that absorb $\mathrm{CO}_{2}$; and (4) attention for other greenhouse gases (OGGS). A process of technology development and diffusion is needed to allow successful progression along these main routes.

\section{Renewable energy offers too little potential up to 2030}

Improved energy efficiency is the basis of emission reduction policy, but is not enough on its own, so that modification of the energy mix is also needed. Even an optimistic scenario in which, alongside economic growth and efficiency improvements in a BAU scenario, allowance is made for an additional policy-driven reduction in energy inten- 
sity, results in a growth in emissions of $0.7 \%$ per year, whereas a reduction of $0.8 \%$ per year is needed in order to achieve the EU $2{ }^{\circ} \mathrm{C}$ target. This means that, in order to achieve the EU target, an extra emission reduction of around $1.5 \%$ per year is needed relative to this optimistic scenario.

There are two options for achieving a far-reaching reduction in fossil $\mathrm{CO}_{2}$ : global alternatives to fossil energy or cleaner fossil energy. The alternatives to fossil energy are: (1) nuclear energy, which currently accounts for $7 \%$ of global primary energy consumption, falling to $5 \%$ in 2030; (2) renewable energy, with a current share of $13 \%$. However, more than half the renewable energy comes from traditional biomass. If renewable energy were to be made an important element in the climate strategy, a contribution would have to come from solar energy, wind power and modern biomass. Bearing in mind the fall in the shares of nuclear energy and traditional biomass, their current total share of $4 \%$ of primary energy consumption would then have to grow to around $34-46 \%$ of what by then will be a much increased primary energy consumption. Chapter 4 shows that this cannot be a realistic strategy.

As the use of coal is unavoidable in the short term, adequate global mitigation requires that gasification technology be widely used for electricity generation, something which will put (further) pressure on the competitiveness of solar energy and wind power. The choice for coal is then simultaneously a choice for the long-term postponement of the use of solar and wind power, except in niche markets. Modern biomass is much more compatible with coal use, and is moreover currently the only realistic low-carbon alternative suitable for use in the transport sector. This means that biomass is for the moment a much more promising option than solar energy and wind power.

In the view of the Council, present policy is focused too much on the use of modern renewable energy within the Netherlands and the EU in the short term, by means of grants and portfolio targets. On the other hand, there are signs of a change of tack, as the open-ended character of some grants is being abandoned.

\section{Recommendation 3}

The Council recom mends a realistic approach to the use of modern renewable energy. The enormous investments on a worldwide scale and the requirement of cost-effectiveness that many countries will set as a condition, imply that the global carbon price will have to be high for a long time before renewable energy brings down em issions very sharply with present technology. For this reason, the Council recommends cautious use of min im um portfolio obligations in the energy supply. 
The Council also concludes that, in the coming decades at least, nuclear energy will form an indispensable part of the world energy supply, both because of the increasing importance being attached internationally to security of energy supplies and because of the required emission reductions. Nuclear energy is safer and more efficient than twenty years ago, though four key problems remain: the waste problem, the proliferation of nuclear weapons and nuclear power stations as a potential supplier or victim of terrorism, their public acceptance and the enormous initial investments required. The limited share taken by nuclear energy in the global energy mix will increase - slightly - only as a result of very major investments, because energy consumption is set to increase explosively at the same time. The choice to be made in the Netherlands is primarily a political one, and will in reality make little difference at international level. In the view of the Council, however, the Netherlands should seek to ensure that the taboo which applies for nuclear energy is not sustained in a post-Kyoto arrangement (as is now the case for Clean Development Mechanism projects, CDM and Joint Implementation projects, JI).

\section{Recommendation 4}

The Netherlands must use its influence to ensure that a post-Kyoto arrangement leaves open the option to support new generations of nuclear energy via CDM (Clean Development Mechanism) and JI (Joint Implementation). Nuclear energy can and will contribute for much of this century (and possibly the entire century) to em ission reduction and security of energy supplies at global level. The Netherlands needs to review its own nuclear options more in terms of greater security of energy supplies in the long term than in term s of the climate, because the influence of Dutch nuclear energy policy on global emission reductions will be minimal.

\section{Energy efficiency and clean fossil energy are urgently needed}

In many countries, the temptation to base electricity generation on coal, with its high emission levels, is irresistible: coal is cheap, stocks are enormous, the energy supply security it gives to the country concerned is an additional bonus and power stations are geared to coal. On the downside, coal contains much more carbon per unit of energy and therefore exacerbates the emission problem. In a dozen coal-based economies such as the US, China, India, Australia, Russia, Indonesia, South Africa and the Ukraine, the emission reduction policy is therefore above all a policy focused on clean fossil energy. Unless emissions from coal use are tackled radically across the world, every climate strategy is doomed to failure.

Energy efficiency can be pursued primarily in the end use and generation of electricity. A major sea change can and must be effected in inefficient and rapidly growing economies. In the electricity sector, major investments will have to be made in this in the near future which will establish the energy structure for a long period, so that there 
is great potential here combined with a closing window of opportunity.

Cleaner fossil energy, especially through $\mathrm{CO}_{2}$ capture and storage, is crucial in a dozen medium-sized and large coal based economies which house roughly two-thirds of the world population. Carbon capture and storage (CCS) is the only emission reduction option in the energy mix which is of interest in these countries during the next five decades. Gasification technology, in addition to local environmental benefits, offers the option of applying CCS at a later stage (first in the OECD countries or, experimentally, in poor countries and then on a wider scale). Precisely where coal is used, CCS can bring about an extra-large reduction effect. Moreover, gasification technology opens the way for a sharp increase in the use of biomass, with electricity or clean transport fuels as the end products.

\section{Recommendation 5}

The Dutch climate strategy needs to focus more on energy efficiency - at home, in Europe and worldwide - and on the international application of gasification technology and carbon capture and storage.

\section{More attention for sinks}

An increase of just $2 \%$ in the absorption capacity of land-based sinks will result in the withdrawal of $1.2 \mathrm{GtC}$ from the atmosphere each year. This will relieve the pressure on investments in clean fossil energy and in expensive modern renewable energy, especially in the coming decades. More attention for sinks will help create the time needed for the gradual replacement of old electricity power stations, for large-scale research and development into carbon-free technologies and for a much more gradual adaptation. This route means halting deforestation, accelerating afforestation and reforestation, greater use of timber in products and buildings, and finally limiting ploughing to where this is needed for planting.

\section{More global attention for OGGS}

In the short term, in particular, it is cost-effective to focus attention on methane and (industrial) $\mathrm{N}_{2} \mathrm{O}$. Until the Kyoto Protocol there was no pricing or policy incentive to focus on OGGS, and there is consequently a great deal of unrealised potential. Moreover, methane reduction is attractive from the perspective of timing because of its shorter period of residence in the atmosphere. The main industrial OGGS to be reduced are fluorohydrocarbons and chlorohydrocarbons. The conditions that apply here somewhat resemble those in the Montreal Protocol (ozone protection).

\section{Technology development and diffusion}

Cheap emission reduction options are available mainly in developing countries in the 
coming decades. Technology diffusion is necessary in order to realise these options. Research and development are also needed to develop genuinely new technologies. However, the Council feels that a clear distinction should be drawn between innovation and implementation. Forced implementation of immature technologies entails high costs which do not justify the small incremental improvements brought about by such a policy. In the period up to around 2030 the market incentives for radical change will remain relatively small owing to the cheap reduction options in poor countries. Precisely because R\&D is so important, the Council distances itself from the 50-50 policy: this policy is neither efficient in bringing about emission reduction, nor effective in engendering $R \& D$.

The R\&D and innovation route pursued by the Netherlands and the EU, which promotes transitions to emission-free technology and transport, needs to be and remain sufficiently ambitious for many decades, and needs to focus on radical new technologies. These efforts by the Netherlands and the EU must be further internationalised, as a minimum in strategic alliances with the US, Canada and Japan. Within the EU, the Sixth Framework Research and Development Programme offers every opportunity for this, while the decision-making process on the Seventh Framework Programme is already at an advanced stage.

\section{Recommendation 6}

The Council recommends that a clear distinction be made between innovation and implementation. Innovation must be encouraged mainly via $R \& D$ and can be achieved to only a limited extent via implementation grants. The 50-50 policy is neither efficient nor effective. The Dutch transition strategy to em ission-free technologies must be embedded in a global climate strategy (and not a purely Dutch strategy) and $m$ ust be related to the globally dom inant priorities ( such as clean fossil energy). This implies different priorities from those geared only to Dutch preferences.

\subsection{THE EFFI CACY OF GLOBAL COORDINATION}

\section{Rich countries (help) pay for emission reductions in poor countries}

The coordination issue relates to who will do what, how intensively and when, or who will pay for this. In the coming decades the biggest task will be to ensure that industrialising and poor countries achieve their economic growth in an emission-efficient way. The marginal costs of emission reduction will remain low in these countries for many decades. A rational allocation of resources thus demands a high concentration of emission reduction efforts in developing countries. This will only happen if the OECD countries ensure the diffusion and further development of the necessary technology 
and pay for all or part of its application. The distribution issue is then concerned with the transfers or other forms of direct or indirect payments to poor countries. To a very limited extent this already happens under the United Nations Framework Convention on Climate Change (UNFCCC) and, in the Kyoto Protocol, via the CDM, under which the rich countries meet their emission reduction obligations through emission reductions in poor countries which have no such obligations.

The Netherlands must link its climate policy to development work. CDM projects arranged under a less bureaucratic and better equipped regime than at present are an obvious means of achieving this. Given that the global emission reduction routes, we can indicate three core focuses for CDM example projects:

- incorporating gasification technology and CCS technology, or enabling these to be incorporated, especially in new power stations;

- curbing deforestation and encouraging reforestation;

- reducing methane emissions (in the coal and gas industry, through fertilisers, sewage sludge, waste and rice cultivation).

\section{Recommendation 7}

The Council recommends that the Netherlands focus its em ission reduction efforts as a priority on the CDM, with special attention for technology diffusion and transfer.

\section{No agreement on the final goal, but agreement on the direction}

Rather than engaging in arguments about what the correct objective should be, parties would do better to reach agreement on what binds them - the direction of climate policy - whilst recognising that views on the ultimate objective can differ at present. Once more knowledge becomes available on the likely damage and on its temporal and geographical localisation, there will be greater clarity concerning the objective to be aimed for and the interests of each of the parties in this. There is furthermore agreement on a global distribution of responsibilities and tasks. The UNFCCC lays down a 'common but differentiated responsibility' for rich and poor. As long as the per capita emissions in rich countries are a multiple of those in poor countries, it is illusory to expect emerging economies to bear the costs of technology diffusion themselves if they receive no local benefits in return in the form of a better local environment or greater energy efficiency. The additional costs of technology diffusion for climate policy will therefore have to be included in the European assessment of climate on objectives and the costs to be incurred in achieving them, or even better in the assessments made in this regard by all developed countries.

\section{The efficacy paradox}

On its own, the Kyoto Protocol is not effective because of the efficacy paradox: what is 
achievable is not effective, and what is effective is not achievable. The Kyoto Protocol owes its broader acceptance to its limited scope and above all its selectiveness (with its focus on countries with an emission reduction obligation). The lesson from Kyoto is that a choice has to be made between broad participation with lesser objectives or narrow participation with more burden some objectives. Effective climate policy requires a combination of the two, because it depends on the product of participations and objective. But the Kyoto approach does provide a useful finger exercise for an emissions trading system, which at least for $\mathrm{CO}_{2}$ did not exist anywhere before Kyoto, supplemented by various mechanisms. This Kyoto approach deserves support. However, it is vital to extend the coalitions supporting this approach and at the same time to recognise that all manner of other approaches to climate policy can also contribute at global level. In the previous chapter this was described as 'multicoloured flexibility'.

\section{Recommendation 8}

The Council believes that the eu, with an active Netherlands within it, must in its own interests promote multilateral coordination, though largely in different ways from those that have been propounded until recently. The EU must reflect on the efficacy paradox: what is achievable globally is not effective, and what is effective is currently not achievable. For the com ing decades the direction of the world climate strategy will be a crucial binding element in the UNFCCC. A multicoloured flexibility of initiatives is an appropriate part of this. Now that the Kyoto approach is working, it is desirable and perhaps possible to expand the coalition of Kyoto countries after 2012, though taking into account the efficacy paradox, in order to avoid the politics of illusion.

\section{Interests of major players as starting point}

The Council believes that global coordination can only succeed if the major players form coalitions, which explicitly take into account their interests in the longer term. Leaving aside altruistic motives, it is above all the anticipated damage that prompts countries to work together. The countries which are expected to suffer the most damage will be manoeuvred into a vulnerable position. In short, it is not the polluter but the victim of pollution who may find themselves forced to pay or to buy off free rider behaviour, at least to some extent.

In order to form a coalition in the face of these diverging interests, parties will have to look for the things that bind them. First and foremost this is the direction of the policy: emission reduction. Other elements are the resources and some conditions: deploying technological resources cost-effectively, preferably via the market mechanism and with as little impact as possible on economic growth. Finally, crucial for climate policy are the interests of securing energy supplies for countries with diverging energy structures and economic growth rates. The time horizon for solving problems 
relating to security of energy supplies is short, which means that these problems are given high priority. Both climate policy and energy supply security impinge directly on interests in relation to energy policy. Climate policy which takes insufficient account of the urgency of energy supply security is doomed to fail. When it comes to energy efficiency, the interests of the climate and energy supply security run parallel, making energy efficiency a potentially promising core focus of policy.

\section{Recommendation 9}

The Dutch climate strategy must as a priority exploit the synergy of the interests of security of energy supply and climate policy, because without this link climate policy will receive insufficient support and will encounter international resistance.

The following core elements are important in the Council's view: (1) achievable results; (2) multicoloured flexibility; (3) the UNFCCC as a framework; (4) stimulating leadership; and (5) the formation of coalitions.

\section{(1) Achievable results make a contribution}

There is little point in seeking to establish the 'post-Kyoto architecture' of the multilateral coordination for a long period at this juncture. Kyoto has shown that timelines with policy consequences lead, due to lack of flexibility, to alienation between UNFCCC parties.

\section{(2) Multicoloured flexibility}

The EU and the Netherlands must be open to initiatives alongside Kyoto, though without abandoning the Kyoto approach. This is why the Council proposes a sort of 'multicultural flexibility' which leaves all UNFCCC parties free to engage in other, more or less ambitious forms of climate policy. Examples might include a no-regret policy (such as improving energy efficiency, something that is also useful even without a climate problem and which has enormous potential in developing countries); no-lose policy (an incentive to emission reduction, but not a sanction); technology development and diffusion; inten sity targets; self-imposed climate policies and measures (PAMS) with accountability; and the higher ambition of emissions trading systems or a carbon price. Just as with the trading policy, it is both possible and attractive to encourage bilateral and regional arrangements for certain aspects of emission reduction, for example as part of existing special relations or development policy. The notion of multicoloured flexibility also implies an alliance not just on vertical measures imposed by governments, but a much greater involvement of the private sector in climate policy. Energyintensive industries and the automotive industry, in particular, have a great deal to contribute. Sectoral agreements can then remove concerns about the undermining of competitiveness for individual companies, provided free-rider behaviour is avoided. 


\section{(3) The UNFCCC is a suitable framework}

The UNFCCC has proved to offer a suitable basis of principles on which to build multilateral coordination. The UNFCCC acts as a foundation that offers negotiating parties opportunities which can be used in a variety of ways over a period of several decades. Parties appreciate their participation (which for far and away the majority of participants is without obligation) in the Conference of the Parties (COP) of the UNFCCC countries, and they meet specific elements of UNFCCC programmes and the (limited) obligations, although interests and perceptions can (still) vary enormously. If a global emission reduction strategy is to be effective, however, a modest degree of organisation and a certain amount of problem-ownership are desirable.

The huge cop meetings could be made more effective through the establishment of a World Climate Organisation (WCO), as a standing organisation backed by permanent diplomatic missions. There would need to be a form of executive body - the Special Climate Council (SCC) referred to in chapter 5 - with a number of permanent members (between five and eight of the largest producers of GHGS) and a number of rotating country members operating under a rotating presidency. This construction would institutionalise the leadership and foster the favourable effects of problem-ownership.

\section{(4) Leadership must stimulate}

In the initial phases, the leadership can act as a catalyst. Leadership requires a willingness to invest, encourage and pay. It is the leader who indicates the urgency, who has to be credible and who has to set an example. Leadership must however remain functional: it must serve as a catalyst, not as a one-sided subsidy tap, and must not become an undermining factor for competitiveness. Leadership is unsuitable, and can even be abused, if interests diverge too widely and/ or there is a lack of willingness among the partners. Less uncertainty in the future will probably lead to a more active stance by parties such as the us, but probably also China and India. This activation could form the basis of a Special Climate Council (SCC) in a future WCO. However, this will mark the end of the self-professed prerogative of leadership by the eu.

\section{(5) Leadership by coalitions}

Leadership could also be exercised by a coalition of major players. The costs of leadership would be more easily borne by such a coalition, because the coalition as a whole could get closer to the optimum balance between costs and benefits than an individual player. The Council sees a coalition of between five and eight of the biggest GHG producers as an effective means of achieving the required emission reductions up to 2050 . The institutionalisation of a scc within a WCO would be an appropriate vehicle for this, though by no means the only option. 


\subsection{HOW A SMALL COUNTRY CAN BE GREAT}

The power of a small country lies in nagging, niggling and encouraging with fresh initiatives. An active international diplomacy which forms a link bridging the wide gap between the major parties can contribute to the required multicoloured flexibility of international obligations and initiatives.

The Netherlands occupies a special position in that it is home to a relatively large number of major multinationals and a high proportion of non-governmental organisations (NGOS). Major corporations will increasingly be held accountable for their social responsibility. Industry can be involved in the multicoloured flexibility referred to above, both via its own marketing initiatives, international variants of covenants and investments in research, as well as through the development of technical standards for products and the production process. For example, the technology platforms subsidised by the EU are better able than the government itself to select promising research priorities and secure commitment to them from the relevant parties.

The Netherlands operates the Top Technology Institute concept (TTI), which has drawn respect from the EU among others. It is a virtual institute that provides a forum for public-private partnership in which businesses, government and knowledge institutes have entered into both an administrative and financial commitment in the ratio of $25 \%, 50 \%$ and $25 \%$, respectively. The initiative for research programmes come from industry; the government performs marginal tests, though the research must be of international top quality. A TTI is a tried and tested means of guaranteeing that a shift in emphasis towards fundamental knowledge development in a bid to achieve an emission-free energy supply does not become stranded in good intentions. In addition, a TTI could provide an economic impetus for the knowledge economy.

\section{Recommendation 10}

The Council recommends a shift in emphasis aw ay from em ission reduction within the Netherlands and tow ards ambitious knowledge development for the long term. By establishing a Top Technology Institute focusing on an em ission-free energy supply, the Netherlands must stimulate fundamental research of the highest international standard. In addition, there is scope for more system atic cooperation with multinational corporations and NGOs for the development of market solutions and original initiatives for climate policy. 


\section{BI BLI OGRAPHY}

Aldy, J. et al. (2003) Beyond Kyoto, advancing the international effort against climate change, Washington D.C.: Pew Center.

Alley, R.B. (2004) Abrupt climate change, Scientific American 291, 5: 40-47.

Buuren, P.J.J. van \& A.M. Laninga-Busch (2005) Ruimte reserveren voor zones langs hoofdinfrastructuur en waterberging, Bouwrecht 4: 281-288.

CEPS (Centre for European Policy Studies) (2005) Tow ards a global climate change regime - priority areas for a coherent EU strategy, Brussels: CEPS.

CIAB/IEA (Coal Industry Advisory Board) (2005) Reducing Greenhouse Gas Em issions, The Future of Coal, Paris.

Commissie Rivierdijken (1977) Rapport Comm issie Rivierdijken .

Commissie Watersnood Maas (Commissie Boertien II) (1994) De Maas terug!

Daniëls, B.W. \& J.C.M. Farla (2006) Potentieelverkenning klimaatdoelstellingen en energiebesparing tot 2020; Analyses met het Optiedocument energie en em issies 2010/2020, Petten/Bilthoven: ECN and MNP.

Easterling, W.E., B.H. Hurd \& J.B. Smith (2004) Coping with global climate change. The role of adaptation in the United States, Pew Center on Global Climate Change.

Egenhofer, C., L. van Schaik \& D. Cornland (2005) Improving the Clean Development Mechanism, Report for presentation at a UNFCCC side event in Montreal, CEPS, CLIPORE.

Elzen, M. den \& M. Meinshausen (2005) Meeting the EU 2 degrees climate target: global and regional emission implications, Bilthoven: RIVM.

European Union (2003) WETO: World Energy, Technology and Climate Policy Outlook 2030, http://europa.eu.int/comm/research/energy/pdf/weto_final_ report.pdf.

European Commission (2000) Communication from the Com mission on the precautionary principle, 2 February 2001.

European Commission (2005) Winning the battle against global climate change, COM 35.

Gielen, D. \& J . Podanski (2004) The Future Role of $\mathrm{CO}_{2}$ Capture in the Electricity Sector, Vancouver, www.iea.org/ Textbase/speech/allspeeches.asp.

Goldemberg, J. (ed.) (2000) World Energy Assessment: Energy and the Challenge of Sustainability, New York: UNDP.

Groothuijse, F.A.G. \& H.F.M.W. van Rijswick (2005) Water en ruimtelijke ordening: meer dan de watertoets! (I), Bouwrecht 42, 3: 193-2 10.

Hawkins, D.G. \& R. H. Williams (2005) Preventing Carbon Lock-in, NRDC, www.princeton.edu/ $\sim \mathrm{cmi} /$ research/Capture/ capturerpt.shtml.

Hitz, S. \& J. Smith (2004) 'Estimating global impacts from climate change', pp. 31-82 in The benefits of climate change policies, Paris: OECD. 
Höhne, N., C. Galleguillos, K. Blok, J. Harnisch \& D. Phylipsen (2003) Evolution of com mitments under the UNFCCC: Involving newly industrialized econom ies and developing countries, Berlin: Umweltbundesamt.

House of Lords (2005) The economics of climate change, London: HMSO.

Hufen, J.A.M. (1998) Draagvlak voor kwantitatief waterbeheer, Bestuurskunde 7, 6: 261-269.

IEA (2004) World Energy Outlook 2004, Paris.

IPCC (Intergovernmental Panel on Climate Change) (2001) Climate change 2001, Third Assessment Report (TAR), Geneva, www.ipcc.ch.

Kets, W. \& G. Verweij (2005) Non-CO Greenhouse gases - all gases count, Discussion Paper 44, The Hague: CPB.

Klijn, F. et al. (2004) Flood-risk Management Strategies for an Uncertain Future: Living with Rhine River Floods in the Netherlands? Ambio 33, 3: 141-147.

Leemans, R. \& B. Eickhout (2004) 'Another reason for concern: regional and global impacts on ecosystems for different level of climate change', Global Environmental Change, 14, 219-228.

Levin, K. \& J . Pershing (2006) 'Climate science 2005. Major new discoveries', WRI Issue Brief, Washington: World Resources Institute.

McFarland. J.R., H.J. Herzog \& H.D. J acoby (2004) The Future of Coal Consumption in a Carbon Constrained World, http:// equestration.mit.edu/bibliography/ economics.html.

McKibbin, W. (2005) Sensible climate policy, Sydney: Lowy Institute, www.lowyinstitute.org./ Publication.asp?pid=212.

Ministerie van Economische Zaken (2005) Nu voor later. Energierapport 2005, The Hague.

MIT (Massachusetts Institute of Technology) (2003) The future of nuclear power; an interdisciplinary MIT study.

MNP (Milieu- en Natuurplanbureau) (2005) Effecten van klimaatverandering in Nederland, Bilthoven.

Pacala, S. \& R. Socolow (2004a) Stabilization Wedges: Solving the Climate Problem for the Next 50 Years with Current Technologies, Science 305, 5686: 968-972.

Pacala, S. \& R. Socolow (2004b) Supporting Online material, www.sciecemag.org/ cgi/ content/ full/305/5686/968/DC1.

Reilly, J., N. Sarofim, S.Paltsev \& R. G. Prinn (2004) The Role of Non-CO, Greenhouse Gases in Climate Policy, mit Joint Program on the Science and Policy of Global Change, Report no 114, web.mit.edu/globalchange/www/MITJPSPGC_Rpt114.pdf.

Reiss, M.J. \& R. Straughan (2001) Improving nature? The science and ethics of genetic engineering, Cambridge: Cambridge University Press.

RIVM (Rijksinstituut voor Volksgezondheid en Milieu) (2004) Risico's in bedijkte termen. Een evaluatie van het beleid inzake de veiligheid tegen overstromen, Bilthoven. 
Rooijers, F.J., I. de Keizer, S. Slingerland, J . Faber, R.C.N. Wit (CE), J. Verbeek, R. van Dorland, A.P. van Ulden, R.W.A. Hutjes, P. Kabat \& E.C. van Ierland (2004) Klimaatverandering, Klimaatbeleid, Inzicht in keuzes voor de Tweede Kamer, Delft: CE, KNMI, Universiteit Wageningen.

Rose, A. \& B. Stevens (1998) 'A dynamic analysis of fairness in global warming policy. Kyoto, Buenos Aires, and Beyond', Journal of Applied Economics 1, 2: 329-362.

Senior, B., J. Adams, T. Espie \& I. Wright (2004) 'Investigation of how Capture and Storage Could Evolve as a Large Scale $\mathrm{CO}_{2}$ Mitigation Option', in: E.S. Rubin, D.W. Keith \& C.F. Gilboy (eds.) Proceedings of 7th International Conference on Greenhouse Gas Control Technologies. Volume 1: Peer-Reviewed Papers and Plenary Presentations, Cheltenham: IEA, uregina.ca/ghgt7/ PDF/ papers/peer/462.pdf.

Stokes, G.M., C.J . Bernier, A.L. Brenkert \& S.J. Smith (2004) Current Carbon Em issions in Context: Final Report to the National Com mission on Energy Policy, Battelle Memorial Institute.

Vries, B.J.M. de (2004) Duurzaam heid in een veranderende wereld, Inaugural lecture, Universiteit Utrecht.

VROM (Ministerie van Volkshuisvesting, Ruimtelijke Ordening en Milieu) (2005) Report on Dutch Climate Change Policy to the European Comm ission under Decision 280/2004/EC, May.

VROM-raad (2002) Minder blauw op straat? Advies over regionaal waterbeheer en ruim telijke ordening in de 21 eeuw, The Hague.

VROM-raad \& AER (2004) Energietransitie: Klimaat voor nieuwe kansen, The Hague.

WB21 (Commissie Waterbeheer 21 e eeuw) (2000a) Waterbeleid voor de 2 le eeuw, Advisory report.

WB21 (2000b) Scenario's externe krachten voor WB21, RIZA, KNMI, WL/ Delft Hydraulics.

WRR (2006) Klimaatstrategie - tussen ambitie en realisme, Report to the government no. 74, Amsterdam: Amsterdam University Press. 
